NBER WORKING PAPER SERIES

\title{
LOCAL EXPOSURE TO SCHOOL SHOOTINGS AND YOUTH ANTIDEPRESSANT USE
}

\author{
Maya Rossin-Slater \\ Molly Schnell \\ Hannes Schwandt \\ Sam Trejo \\ Lindsey Uniat \\ Working Paper 26563 \\ http://www.nber.org/papers/w26563
}

\author{
NATIONAL BUREAU OF ECONOMIC RESEARCH \\ 1050 Massachusetts Avenue \\ Cambridge, MA 02138 \\ December 2019
}

We thank Janet Currie, David Cutler, Daniel Grossman, Anupam (Bapu) Jena, Phillip Levine, Michelle Mello, Don Mordecai, Ciaran Phibbs, David Studdert, and seminar participants at Stanford University, the University of Oregon, the 2019 Whistler Health Economics Summit, the 2019 American Society of Health Economists Annual Conference, and the 2019 NBER Summer Institute. The statements, findings, conclusions, views, and opinions contained and expressed herein are not necessarily those of IQVIA or any of its affiliated or subsidiary entities. The views expressed herein are those of the authors and do not necessarily reflect the views of the National Bureau of Economic Research.

NBER working papers are circulated for discussion and comment purposes. They have not been peer-reviewed or been subject to the review by the NBER Board of Directors that accompanies official NBER publications.

(C) 2019 by Maya Rossin-Slater, Molly Schnell, Hannes Schwandt, Sam Trejo, and Lindsey Uniat. All rights reserved. Short sections of text, not to exceed two paragraphs, may be quoted without explicit permission provided that full credit, including $\odot$ notice, is given to the source. 
Local Exposure to School Shootings and Youth Antidepressant Use

Maya Rossin-Slater, Molly Schnell, Hannes Schwandt, Sam Trejo, and Lindsey Uniat

NBER Working Paper No. 26563

December 2019

JEL No. I18,I31,J13

\section{$\underline{\text { ABSTRACT }}$}

While over 240,000 American students experienced a school shooting in the last two decades, little is known about the impacts of these events on the mental health of surviving youth. Using large-scale prescription data from 2006 to 2015, we examine the effects of 44 school shootings on youth antidepressant use in a difference-in-difference framework. We find that local exposure to fatal school shootings increases youth antidepressant use by 21.4 percent in the following two years. These effects are smaller in areas with a higher density of mental health providers who focus on behavioral, rather than pharmacological, interventions.

Maya Rossin-Slater

Department of Medicine

Stanford University School of Medicine

615 Crothers Way

Encina Commons, MC 6019

Stanford, CA 94305-6006

and NBER

mrossin@stanford.edu

Molly Schnell

Department of Economics

Northwestern University

2211 Campus Drive

Evanston, IL 60208

and NBER

schnell@northwestern.edu

Hannes Schwandt

SESP

Northwestern University

2120 Campus Drive

Evanston, IL 60208

and CEPR

schwandt@northwestern.edu

\author{
Sam Trejo \\ Stanford University \\ Graduate School of Education \\ 485 Lasuen Mall \\ Stanford, CA 94305 \\ samtrejo@stanford.edu \\ Lindsey Uniat \\ Department of Economics \\ Yale University \\ 28 Hillhouse Ave \\ New Haven, CT 06511 \\ lindsey.uniat@yale.edu
}




\section{Introduction}

School shootings have become frequent tragedies in the United States. There have been over 234 shootings at primary and secondary schools since the shooting at Columbine High in April 1999, resulting in the loss of 144 lives (Cox et al., 2018). Public attention often focuses on the victims who were killed, but an important and understudied question is how survivors fare in the subsequent months and years. While over 240,000 students were on school grounds during a shooting in the past 20 years, little is known about the impacts of these events on the mental health of surviving youth. ${ }^{1}$ The large private and social costs of mental illness - especially during childhood - suggest that estimates of the effects of school shootings on mental health may be critical for assessing the overall welfare consequences of these events. ${ }^{2}$

In this paper, we examine the impacts of local exposure to school shootings on an important indicator of youth mental health: the use of prescription antidepressants. ${ }^{3}$ To do so, we combine data on the near universe of antidepressant prescriptions filled at U.S. retail pharmacies between January 2006 and March 2015 with information on 44 school shootings that occurred between January 2008 and April 2013. Our empirical strategy compares the number of antidepressant prescriptions written by providers practicing 0-5 miles from a school that experienced a shooting ("shooting-exposed areas") to the number of prescriptions written by providers practicing 10-15 miles away ("reference areas"), both before and after the shooting. ${ }^{4}$ We include month-by-year and school-by-area fixed effects in all specifications,

\footnotetext{
${ }^{1}$ Leading scholars across multiple disciplines have recently called for more research on the impacts of shootings on survivors (Rowhani-Rahbar et al., 2019; Iancu et al., 2019; Travers et al., 2018).

${ }^{2}$ Mental illness in childhood has been shown to have negative long-term impacts on human capital formation and adult economic outcomes, exceeding the impacts of poor physical health conditions such as childhood epilepsy and low birth weight (Currie and Stabile, 2006; Currie et al., 2010; Goodman et al., 2011). Recent estimates suggest that depression alone costs the U.S. economy over $\$ 210$ billion per year in lost productivity, missed days of work, and direct health care costs stemming from related physical and mental illnesses (Greenberg et al., 2015).

${ }^{3}$ Antidepressants are frequently used to treat mental health conditions that may be particularly relevant for shooting survivors, including major depressive disorder and post-traumatic stress disorder (American Psychiatric Association, 2004, 2010).

${ }^{4}$ We demonstrate that our results are robust to using alternative distances between schools and providers to define shooting-exposed areas and to using providers located in the vicinity of matched control schools
} 
thereby controlling for overall trends in antidepressant use and all time invariant differences across locations.

We find that fatal school shootings have large and persistent impacts on the mental health of local youth. In the two years following a fatal school shooting, the monthly number of antidepressant prescriptions written to individuals under age 20 is 21.3 percent higher in the shooting-exposed relative to the reference areas. Consistent with clinical practice guidelines regarding minimum treatment duration, this effect persists when we extend the post-shooting observation window to three years (American Psychiatric Association, 2004, 2010). ${ }^{5}$ We find no effects of non-fatal school shootings on youth antidepressant use. We further find no effects of fatal school shootings on antidepressant use among adults.

As communities may differ in their capacity to cope with shooting-related trauma, we investigate heterogeneity in effects by the local availability of mental health care resources. We find that school shootings have smaller effects on youth antidepressant use in areas with a higher density of mental health providers who focus on behavioral, rather than pharmacological, interventions (i.e., psychologists and social workers). ${ }^{6}$ This pattern suggests that youth in areas with a higher density of non-prescribing mental health providers are either less affected by school shootings or are more likely to rely on non-pharmacological treatment in the aftermath of a shooting. While the relative effectiveness of behavioral and pharmacological mental health treatment is still debated (e.g., Ross et al., 2019, Cipriani et al., 2018, Cronin et al., 2017), substitution toward non-drug treatment could be welfare-improving if antidepressants are used inappropriately to treat survivors of school shootings.

Our study is the largest analysis of the impacts of school shootings on youth mental health to date. Despite the prevalence of school shootings in the United States, previous that did not experience a shooting as alternative reference areas.

${ }^{5}$ This persistence might also reflect a deterioration in mental health and community well-being resulting from increased firearm purchases and gun-related deaths following a shooting (Studdert et al., 2017; Levine and McKnight, 2017).

${ }^{6}$ Notably, we find no difference in effects between areas with high versus low densities of providers who commonly prescribe antidepressants to children (i.e., physicians in psychiatry, family medicine, and pediatrics). This evidence suggests that physicians have the capacity to treat youth exposed to school shootings even in areas with a relatively low density of such providers. 
work on their mental health consequences is limited to studies of students at several schools in the 1980s and 1990s. ${ }^{7}$ These studies suggest that such events are associated with adverse psychological outcomes, but they rely on small samples, often lack control groups or preexposure data, and use surveys that may be subject to selective response bias (Lowe and Galea, 2017; Travers et al., 2018; Bharadwaj et al., 2017). Furthermore, it may be hard to extrapolate correlations from 30-40 years ago to events happening today. In contrast, we examine the effects of 44 school shootings that occurred across the United States between 2008 and 2013, exploit a quasi-experimental design that controls for fixed differences across locations and trends in antidepressant use, and use comprehensive prescription data that is not subject to survey response bias.

Our work further contributes to the literature on the causal determinants of poor mental health among children. Despite evidence that childhood mental illness can have lasting consequences that often exceed those attributed to poor physical health (Currie and Stabile, 2006; Currie et al., 2010; Goodman et al., 2011), causes of poor mental health in childhood are not well understood. Prior work has found a positive association between exposure to various forms of violence- such as neighborhood crime, domestic violence, and school bullying — and mental illness among children. ${ }^{8}$ However, exposure to these sources of violence is correlated with other determinants of mental health such as economic insecurity (e.g., Pah et al., 2017), thereby making causal inference challenging. ${ }^{9}$ Furthermore, the literature on resilience documents children's ability to "bounce back" after trauma (e.g., Agaibi and Wilson, 2005; Goldstein and Brooks, 2005), implying that whether and how much exposure

\footnotetext{
${ }^{7}$ For example, see: Pynoos et al. (1987); Nader et al. (1990); Schwarz and Kowalski (1991a,b, 1992b,a); Schwarz et al. (1993); Sloan et al. (1994); Stretesky and Hogan (2001); Brener et al. (2002); Addington (2003).

${ }^{8}$ For example, see: Lowe et al. (2015); Breslau et al. (1998); Fowler et al. (2009); Krug et al. (2002); Flannery et al. (2004); Janosz et al. (2008); Mrug et al. (2008).

${ }^{9}$ Moreover, it is possible that school shootings have different effects on youth mental health relative to other types of violence. A recent study of police killings of African Americans found a deterioration in the self-reported mental health of black adults in the general population, due to communal bereavement and increased fear and vigilance (Bor et al., 2018). Analogously, youth exposed to school shootings may suffer differentially because of the direct connection they feel to victims in their local community and the loss of a sense of security at their schools.
} 
to violence affects the mental health of youth are ultimately empirical questions. Our results indicate that exposure to a single violent event can have lasting impacts on youth mental health.

\section{Data}

Data on antidepressant prescriptions from January 2006 to March 2015 come from the IQVIA Xponent database, a prescriber-level panel covering prescriptions filled at most U.S. retail pharmacies. ${ }^{10}$ In contrast to typical claims data sets that cover either one or a few insurers, the IQVIA data cover the near universe of prescriptions irrespective of insurance coverage or type. For each prescriber, the data contain the number of antidepressant prescriptions written in each month to individuals in binned age groups. ${ }^{11}$ Our primary analysis focuses on antidepressants prescribed to youth, whom we define as individuals under age 20 (i.e., aged 0-19). The data further contain prescriber practice addresses in 2014 from the American Medical Association. We use these addresses to calculate distances between providers and schools.

Information on school shootings comes from the Washington Post school shootings database, which contains all acts of gunfire at primary and secondary schools during school hours since the Columbine High massacre on April 20, 1999. ${ }^{12}$ The database excludes shootings at afterhours events, accidental discharges that caused no injuries to anyone other than the person handling the gun, and suicides that occurred privately or posed no threat to other students. For each shooting, the data include information on the date, the school's name and address, the number of victims who were killed or injured, the gender and age of the shooter(s), and whether or not the shooter(s) died.

\footnotetext{
${ }^{10}$ IQVIA obtains this data directly from over 90 percent of all retail pharmacies and imputes prescriptions for missing pharmacies to match industry totals.

${ }^{11}$ Age is provided in the following bins: 0-2, 3-9, 10-19, 20-39, 40-59, 60-64, 65-74, 75-84, and 85+.

${ }^{12}$ To compile the database, reporters used LexisNexis, news articles, open-source databases, law enforcement reports, information from school websites, and calls to schools and police departments. The database is updated as facts emerge about individual cases. The version of the database used in this paper is from June 20, 2018.
} 
In addition to information on the shooting itself, the Washington Post data further contain characteristics and basic student socio-demographics for the affected schools. For example, the data include information on grade levels, type of school (e.g., public or private), the racial composition of students, and the share of students receiving free or reduced price lunch. To examine how schools that experienced a shooting compare to the average U.S. school, we supplement the Washington Post data with school and district characteristics for all primary and secondary schools in the United States for the 2009-2010 school year from the Stanford Education Data Archive (Reardon et al., 2017). As discussed in Section 3.1, we also use these characteristics to select schools that are observationally similar to schools that experienced a shooting as an alternative control group.

To allow for at least two years of prescription data before and after each shooting, we consider the 48 school shootings that occurred between January 2008 and April 2013. For each of these events, we calculate the monthly number of antidepressant prescriptions written to individuals under age 20 by providers practicing in two areas: a shooting-exposed area of 0-5 miles from the school and a reference area of 10-15 miles from the school. We calculate these monthly totals for the two years surrounding each shooting. We only keep data for the first shooting that occurred at a given school since 1999 (46 school shootings over our sample window) and for schools with at least one antidepressant prescription written to an individual under 20 by a provider practicing in the shooting-exposed area in each of the relevant 48 months (44 school shootings). The school shootings included in our main analysis are listed in Appendix Table A1.

While comprehensive, the IQVIA data are not without shortcomings. First, we only observe the number of prescriptions, not the number of pills or strength of the medication provided with each script. While the number of scripts could increase without the total quantity of antidepressants dispensed rising, more frequent but smaller prescriptions would suggest increased monitoring that in itself is indicative of worsening mental health (American Psychiatric Association, 2010). Second, since the data are collected from pharmacies, 
they do not include information on the number of patients seen by each provider. As we therefore do not have the population base necessary to construct prescription rates, we use log antidepressant prescriptions as our main outcome variable. As an alternative outcome, we consider antidepressant prescription rates calculated as the number of antidepressant prescriptions written to individuals under by providers practicing in a given area divided by the number of individuals under age 20 living in the same area. To construct these population measures, we aggregate block group-level population counts from the 2010 census across all block groups within 0-5 and 10-15 miles of each school. ${ }^{13}$

Since April 1999, the number of school shootings in the United States has ranged from five in 2002 to 17 in the first five months of 2018 (see Appendix Figure A1). A total of 240,718 students were enrolled in schools that experienced a shooting over this time period. Among the 44 school shootings in our analysis, Table 1 shows that an average of 0.66 victims were injured in each event and 15 resulted in at least one victim death ("fatal" shootings). Among fatal shootings, an average of 2.80 victims were killed. Shooters were on average 20.4 years old, 91 percent of shooters were male, and 14 percent of events resulted in a shooter's death. Relative to the average U.S. school, schools that experienced a shooting on average had higher enrollment, were less likely to be private, were more likely to only have high school grades, and had a higher share of black students. There were no significant differences in average characteristics between schools with fatal and non-fatal shootings.

Finally, to examine heterogeneity in effects by the local availability of mental health care resources we use data on the locations of child mental health providers from the Centers for Disease Control and Prevention (CDC). ${ }^{14}$ For each county, the data provide the number of pediatricians, family physicians, psychiatrists, psychologists, and licensed social workers in 2015 per 1,000 children aged $0-17$. As an alternative measure of provider density, we also calculate the number of providers in the IQVIA data who prescribed at least one antide-

\footnotetext{
${ }^{13}$ The census reports population counts for individuals aged $0-17$ and individuals aged 18 and above. For each area, we estimate the population under age 20 by assuming that the population of individuals aged 18 and 19 is $\frac{2}{18}$ of the population aged $0-17$.

${ }^{14}$ Available at https ://www.cdc.gov/childrensmentalhealth/stateprofiles-providers.html.
} 
pressant to an individual under age 20 in 2010 per individuals under age 20 in each school's shooting-exposed area.

\section{Effects of school shootings on youth antidepressant use}

To examine changes in youth antidepressant use surrounding school shootings, we begin by plotting monthly antidepressant prescription rates for individuals under age 20 in the two years surrounding a school shooting. We plot prescription rates separately for the shootingexposed and reference areas and separately for fatal and non-fatal shootings. We further plot linear fits of the data using only pre-shooting observations; these lines provide counterfactuals for how prescriptions are expected to have progressed in the absence of a school shooting.

As shown in Figure 1, antidepressant use in the shooting-exposed areas increases dramatically following a school shooting. There is no apparent trend break in the reference areas. The increase in antidepressant prescription rates in the shooting-exposed areas is noticeably larger following fatal than non-fatal shootings. Remarkably, antidepressant prescription rates remain at elevated levels in the shooting-exposed areas through the end of the observation period.

We formalize this comparison between changes in antidepressant prescriptions following a school shooting across the shooting-exposed and reference areas using a difference-indifference design. In particular, we estimate the following equation separately for fatal and non-fatal school shootings:

$$
\ln \left(R X_{\text {sta }}\right)=\beta_{0}+\beta_{1} \text { Post }_{t}+\beta_{2} \text { Post }_{t} \times S E_{a}+\sigma_{t}+\delta_{s} \times S E_{a}+\epsilon_{s t a}
$$

where $\ln \left(R X_{s t a}\right)$ denotes the natural log of the number of antidepressant prescriptions written to individuals under age 20 in area $a$ of school $s$ in month $t$, Post ${ }_{t}$ is an indicator that

equals one for months in or after a school shooting and zero otherwise, $S E_{a}$ is an indicator that equals one for shooting-exposed areas and zero for reference areas, $\sigma_{t}$ is a vector of 
month-by-year fixed effects, $\delta_{s} \times S E_{a}$ is a vector of school-by-area fixed effects, and $\epsilon_{s t a}$ is an error term. Standard errors are clustered at the school-by-area level. As we expect the prescribing patterns of providers to be more affected by a school shooting when a larger share of their patient base is directly exposed to the event, we weight these regressions by total school enrollment.

Panel A of Table 2 presents results from estimation of Equation (1). Since the outcome is $\log$ antidepressant prescriptions, our coefficient of interest, $\beta_{3}$, measures the percentage difference in the post-shooting change in the number of antidepressant prescriptions written to individuals under age 20 between the shooting-exposed and reference areas. As shown in Column (1), the average monthly number of antidepressant prescriptions written to individuals under age 20 is 21.3 percent higher in the shooting-exposed areas relative to the reference areas in the two years after a fatal shooting versus the two years before. When extending the post-shooting observation window to three years (Column (2)), we observe a 24.5 percent increase in the average monthly number of antidepressant prescriptions written for youth. We find no statistically significant changes in youth antidepressant use following non-fatal school shootings (Columns (3)-(4)). As shown in Panel B, our results are very similar in percentage terms when we instead use prescription rates as the outcome variable.

Our difference-in-difference strategy requires that prescriptions would have shown similar trends across the shooting-exposed and reference areas in the absence of a school shooting. To examine the validity of this parallel trends assumption and to explore the time path of effects, we also estimate quarterly event study specifications. ${ }^{15}$ In particular, we estimate the following equation separately for fatal and non-fatal school shootings:

$$
\begin{array}{r}
\ln \left(R X_{\text {sta }}\right)=\pi_{0}+\sum_{k=-8, k \neq-1}^{k=7} \rho_{k} \mathbf{1}\left[q(t)-s^{*}=k\right] \\
+\sum_{k=-8, k \neq-1}^{k=7} \tau_{k} \mathbf{1}\left[q(t)-s^{*}=k\right] \times S E_{a}+\sigma_{t}+\delta_{s} \times S E_{a}+\epsilon_{s t a}
\end{array}
$$

\footnotetext{
${ }^{15}$ We define the quarter of the shooting as the three-month period starting with the month of the shooting.
} 
where $s^{*}$ denotes the quarter of the shooting, $q(t)$ is the quarter assigned to each year-month, $\mathbf{1}\left[q(t)-s^{*}=k\right]$ is an indicator that equals one for quarter $k$ relative to the shooting and zero otherwise, and all other variables are defined as in Equation (1). We are interested in the estimates of $\tau_{k}$, which measure the percentage differences in the number of antidepressant prescriptions written to individuals under age 20 between the shooting-exposed and reference areas in each of the quarters surrounding a school shooting relative to the quarter before the shooting.

Estimates of $\tau_{k}$ are presented in Figure 2. Relative to the quarter before a fatal school shooting, antidepressant prescriptions increase by nearly 30 percent within six months and remain at this elevated level for up to two years (Figure 2a). Appendix Figure A2a demonstrates that this effect persists when we extend the post-shooting observation window to three years. As in Table 2, Figure 2b and Appendix Figure A2b show that antidepressant prescriptions for youth are not affected by non-fatal school shootings.

\subsection{Robustness}

In our main specification, we assume that providers practicing 0-5 miles from a school that experienced a shooting are "treated" whereas those practicing 10-15 miles away are not. However, it is ex ante unclear how close a provider needs to practice to a school in order to treat affected patients. As shown in Figure 1, there are no observable changes in antidepressant prescriptions written by providers practicing 10-15 miles from affected schools, suggesting that these providers are in fact "untreated." While there is an observable increase in antidepressant prescriptions written by providers practicing $0-5$ miles from the school, our results will understate the true effects if some of these providers are also untreated.

To ensure that our results are not driven by the choice of distance used to define shootingexposed areas, we assess the robustness of our results to defining shooting-exposed areas using alternative distances between providers and schools. Specifically, we re-estimate Equation (1) using different definitions of shooting-exposed areas $(0-1,0-2, \ldots, 0-9$ miles from a school) 
while keeping the reference areas the same as in the main analysis (i.e., providers located 10-15 miles away). As shown in Appendix Figure A3, the effects become more precise as we include prescribers practicing in a larger area. The estimated effect of school shootings on youth antidepressant use peaks when defining the treatment area as 0-4 miles from a school, but the point estimate is very similar and not statistically different for our primary definition of 0-5 miles. As expected, the effects gradually decline as one subsequently adds providers practicing further away.

Our primary analysis uses providers located slightly further away from an affected school as a control group, as these providers are expected to treat similar types of patients as providers who practice very close to the affected school. However, if areas 10-15 miles away from schools are very different than areas within five miles (e.g., areas further away may be more rural), then providers in these areas might not serve as good reference groups. We note that all of our specifications include a fixed effect for each school-by-area group, thereby controlling for all time invariant differences across locations. Furthermore, Figure 2 demonstrates that antidepressant prescriptions written for youth experience similar trends in both areas in the months before a shooting.

Nevertheless, to ensure that our results are not driven by the choice of reference areas, we examine the robustness of our results to using prescriptions written by providers practicing within five miles of observationally similar schools that did not experience a shooting as control groups. To identify suitable control schools, we consider all primary and secondary schools in the United States in the 2009-2010 school year and estimate a logistic regression of an indicator denoting whether each school experienced a school shooting since 1999 on a range of school and district-level characteristics. ${ }^{16}$ We then select as control schools the 100 schools with the highest predicted shooting scores that are not in the same district as any school that experienced a shooting, separately for the schools with fatal and non-fatal shootings.

\footnotetext{
${ }^{16}$ Output from this regression is provided in Appendix Table A2.
} 
Using these control schools as alternative reference areas, we estimate the following equation:

$$
\ln \left(R X_{s t}\right)=\gamma_{0}+\gamma_{1} \text { Post }_{t}+\sigma_{t}+\kappa_{s}+u_{s t}
$$

where $\ln \left(R X_{s t}\right)$ denotes the natural log of the number of antidepressant prescriptions written to individuals under age 20 by providers practicing within five miles of school $s$ in month t, Post $t_{t}$ is an indicator for the post-shooting time period for shooting-exposed schools and equals zero for all observations for the control schools, $\sigma_{t}$ is a vector of month-by-year fixed effects, $\kappa_{s}$ is a vector of school fixed effects, and $u_{s t}$ is an error term. We cluster standard errors by school and weight the regressions by school enrollment.

As shown in Appendix Table A3, the results using these alternative control groups are very similar to those from our main analysis. In fact, we cannot reject that the estimated effects of school shootings on youth antidepressant use are the same across the two specifications. We also present the corresponding event study estimates from this alternative specification, which are overlaid with those from our baseline model in Appendix Figure A4. The time path and magnitude of effects are very similar across the two specifications.

We conduct three additional robustness checks. First, to ensure that no single event is driving our results, we examine the sensitivity of our estimates to separately dropping each of the 10 states in which we observe fatal school shootings. As shown in Appendix Table A4, our estimates are very stable regardless of which state is excluded. Second, to ensure that our results are not driven by confounding trends in local prescribing behavior or interactions with the health care system, we examine the effects of school shootings on the other class of prescriptions available in our IQVIA sample: opioids. ${ }^{17}$ As shown in Appendix Figure A5, we find no significant impacts of either fatal or non-fatal school shootings on opioid prescriptions written for youth. Finally, to verify that our results are not driven by

\footnotetext{
${ }^{17}$ We note that opioid prescriptions for youth are nearly as common as antidepressant prescriptions: according to the IQVIA data, there were 10.3 million antidepressant prescriptions for individuals under age 20 across the entire United States in 2010 compared to 9.1 million opioid prescriptions for the same age group in the same year. There is therefore scope for opioid use to respond if individuals were to have greater interaction with the health care system.
} 
confounding trends in treatment for underlying mental health problems due to increased awareness of mental illness, we examine the effects of school shootings on antidepressant use among adults. ${ }^{18}$ As shown in Appendix Figure A6, we find no evidence that antidepressant prescriptions for individuals aged 20 and older increase following a local school shooting.

\section{Heterogeneity by mental health care resources}

Local areas may vary in their capacity to cope with trauma in the aftermath of a school shooting. To investigate whether the impacts of school shootings on youth antidepressant use differ by the availability of local mental health care resources, we examine how our estimates vary across locations with differing densities of providers who treat mental health problems among children. As different types of providers differ in their focus on pharmacological versus behavioral treatment, we consider both the local density of prescribing providers (physicians in family medicine, pediatrics, and psychiatry) and non-prescribing providers (psychologists and social workers). ${ }^{19}$ As outlined in Section 2, these provider densities come from the CDC and measure provider counts per 1,000 children in each county.

Table 3 presents estimates from an augmented version of Equation (1) that includes a triple interaction between county-level measures of provider density, the indicator denoting shooting-exposed areas, and the post-shooting indicator. We include the density measures either as continuous variables (Columns (2)-(4)) or as indicators denoting terciles across shooting-exposed counties (Columns (5)-(7)). As the density of prescribing and nonprescribing practitioners is highly correlated across locations (see Appendix Figure A7), in some specifications we include interactions with both density measures (Columns (4) and (7)). For ease of comparison, Column (1) replicates our baseline results from Table 2. Event

\footnotetext{
${ }^{18}$ The mental health of adults could also be affected by school shootings. This analysis can therefore also be viewed as an alternative outcome.

${ }^{19}$ Although a few states have recently expanded their scope of practice legislation to allow certain psychologists to prescribe some medications, prescribing has traditionally been limited to physicians. Furthermore, while physicians can in principle provide psychotherapy in conjunction with pharmacological treatment, the vast majority of physicians - even those who specialize in psychiatry - no longer provide behavioral therapy.
} 
study analogs by terciles of prescriber and non-prescriber densities are provided in Appendix Figure A8.

Looking first to Columns (2) and (5) of Table 3, we see that there are no significant differences in the effects of fatal school shootings on youth antidepressant use across counties with differing densities of prescribing providers. As shown in Appendix Figure A8a, the time path and magnitude of effects are strikingly similar across areas in each tercile of the distribution of prescriber densities. As we would expect to see smaller effects on medication use in areas with a lower density of prescribing providers if providers in such areas were capacity constrained, these results suggest that prescribers have scope to treat shootingrelated trauma both in areas with high and low densities of providers who can prescribe. ${ }^{20}$

In contrast, we find that areas with a higher density of non-prescribing practitioners experience significantly smaller increases in youth antidepressant use following a fatal school shooting (Columns (3) and (5) of Table 3). This is true even when controlling for the density of prescribing practitioners within the county (Columns (4) and (7)). As shown in Appendix Figure A8b, areas with the highest density of psychologists and social workers see no significant changes in youth antidepressant use following a fatal school shooting; rather, the increases in antidepressant use that we observe are concentrated in areas in the middle and bottom terciles of the distribution of non-prescriber densities. This finding is consistent with the possibility that areas with more psychologists and social workers may rely on nonpharmacological treatment, such as cognitive behavioral therapy, to treat shooting-induced trauma.

Since mental health providers are not randomly assigned across counties, it is possible that these patterns could be driven by other differences across locations that are systematically correlated with the availability of mental health care resources. ${ }^{21}$ For example, if school

\footnotetext{
${ }^{20}$ Appendix Figure A7 shows that the county-level density of prescribing providers as reported by the CDC is highly correlated with the density of providers in each school's shooting-exposed area that we observe prescribing antidepressants to individuals under age 20 in the IQVIA data. Our results are therefore very similar if we instead use the density of prescribers from the IQVIA data (see Appendix Table A5).

${ }^{21}$ The school shootings included in our main analysis occurred in 39 different counties. To ensure that our results are not driven by any particular location, Panel C of Appendix Table A4 replicates Column (4) of
} 
shootings were less severe (e.g., had fewer fatalities) in places with a higher density of nonprescribing providers, then we could observe smaller effects on antidepressant use in those areas simply due to differences in the severity of the "treatment." If anything, however, our data indicate that school shootings in counties with a higher density of non-prescribing providers resulted in slightly more victim fatalities (correlation coefficient of 0.129). While other factors, such as income, may also correlate with cross-sectional variation in mental health resources, we note that confounding factors must be correlated with the density of non-prescribing providers conditional on the density of providers who can prescribe.

\section{Discussion and conclusion}

Understanding the mental health consequences of school shootings is critical both for informing cost-benefit analyses of policies aimed at reducing gun violence and for designing programs to help mitigate the effects on survivors. Accordingly, leading scholars across multiple disciplines have recently issued calls for more evidence on the impacts of shootings on survivors (Rowhani-Rahbar et al., 2019; Iancu et al., 2019; Travers et al., 2018).

By examining the effects of 44 shootings at primary and secondary schools across the United States, this study provides the largest analysis of the impacts of school shootings on youth mental health to date. We find that the number of antidepressant prescriptions written to individuals under age 20 by providers located within five miles of a school that experienced a fatal shooting are 21.4 percent higher than the number written by providers located 10-15 miles away in the two years following the shooting versus the two years before. This effect persists when extending the post-shooting observation window to three years. We further document that the effects are smaller in areas with a higher density of psychologists and social workers, suggesting that behavioral treatment may serve as a substitute to antidepressant prescriptions in places that have a higher capacity to provide non-pharmacological treatment.

Increases in antidepressant use following a school shooting could be driven either by inTable 3 excluding one state at a time. The results are very stable regardless of which state is excluded. 
creased incidence of mental illness (i.e., new pathology) or increased treatment of existing pathology. Although we cannot definitely identify the relative contributions of these mechanisms, three additional findings suggest that new pathology is likely a contributing factor. First, we find no effects of local exposure to school shootings on antidepressant use among adults. If school shootings simply raised awareness of mental illness and increased screening in local communities, then we would expect to find similar effects among children and adults. Second, we find no effects of school shootings on opioid prescriptions written for youth. If the effects on antidepressant use were driven solely by additional screening and subsequent interactions with the health care system, then we would expect to find effects on other medication classes. Finally, we find no differences in effects across areas with differing densities of prescribers. If school shootings only led to treatment of previously untreated pathology, then we would expect the effects to be larger in areas with greater undertreatment using medication in the pre-period - that is, areas with fewer prescribers.

Taken together, our results demonstrate that local exposure to fatal school shootings leads to significant and persistent increases in antidepressant use among American youth. While sizable, the increases in antidepressant use that we document are unlikely to capture the full mental health consequences of these events: if school shootings increase the use of non-pharmacological treatment, the use of pharmacological treatment with medications other than antidepressants, or the prevalence of untreated mental illness, then the true effects of school shootings on youth mental health will be even larger. Furthermore, to the extent that school shootings impact students' ability to feel secure and learn at school, exposure to these events could lead to worse behavioral, educational, and economic outcomes among youth. As communities continue to grapple with the aftermath of school shootings, more work is needed to assess the full costs of these events for surviving youth. 


\section{References}

Addington, Lynn A, "Students' fear after Columbine: Findings from a randomized experiment," Journal of Quantitative Criminology, 2003, 19 (4), 367-387.

Agaibi, Christine E and John P Wilson, "Trauma, PTSD, and resilience: A review of the literature," Trauma, Violence, \& Abuse, 2005, 6 (3), 195-216.

American Psychiatric Association, "Practice Guideline for the Treatment of Patients with Acute Stress Disorder and Posttraumatic Stress Disorder," Technical Report 2004.

_ , "Practice Guideline for the Treatment of Patients with Major Depressive Disorder, 3rd Edition," Technical Report 2010.

Bharadwaj, Prashant, Mallesh M Pai, and Agne Suziedelyte, "Mental health stigma," Economics Letters, 2017, 159, 57-60.

Bor, Jacob, Atheendar S Venkataramani, David R Williams, and Alexander C Tsai, "Police killings and their spillover effects on the mental health of black Americans: a population-based, quasi-experimental study," The Lancet, 2018.

Brener, Nancy D, Thomas R Simon, Mark Anderson, Lisa C Barrios, and Meg L Small, "Effect of the incident at Columbine on students' violence-and suicide-related behaviors," American Journal of Preventive Medicine, 2002, 22 (3), 146-150.

Breslau, Naomi, Ronald C Kessler, Howard D Chilcoat, Lonni R Schultz, Glenn C Davis, and Patricia Andreski, "Trauma and posttraumatic stress disorder in the community: the 1996 Detroit Area Survey of Trauma," Archives of General Psychiatry, 1998, 55 (7), 626-632.

Cipriani, Andrea, Toshi A Furukawa, Georgia Salanti et al., "Comparative efficacy and acceptability of 21 antidepressant drugs for the acute treatment of adults with major depressive disorder: a systematic review and network meta-analysis," The Lancet, 2018, 391 (10128), 1357.

Cox, John W, Steven Rich, Allyson Chiu, John Muyskens, and Monica Ulmanu, "More than 228,000 students have experienced gun violence at school since Columbine," Washington Post, nov 2018.

Cronin, Christopher, Matthew Forsstrom, and Nicholas W Papageorge, "Mental Health, Human Capital and Labor Market Outcomes," 2017). University of Notre Dame, unpublished manuscript.

Currie, Janet and Mark Stabile, "Child mental health and human capital accumulation: the case of ADHD," Journal of Health Economics, 2006, 25 (6), 1094-1118.

_, _, Phongsack Manivong, and Leslie L Roos, "Child health and young adult outcomes," Journal of Human Resources, 2010, 45 (3), 517-548. 
Flannery, Daniel J, Kelly L Wester, and Mark I Singer, "Impact of exposure to violence in school on child and adolescent mental health and behavior," Journal of Community Psychology, 2004, 32 (5), 559-573.

Fowler, Patrick J, Carolyn J Tompsett, Jordan M Braciszewski, Angela J Jacques-Tiura, and Boris B Baltes, "Community violence: A meta-analysis on the effect of exposure and mental health outcomes of children and adolescents," Development and Psychopathology, 2009, 21 (1), 227-259.

Goldstein, Sam and Robert B Brooks, Resilience in Children, Springer, 2005.

Goodman, Alissa, Robert Joyce, and James P. Smith, "The long shadow cast by childhood physical and mental problems on adult life," Proceedings of the National Academy of Sciences, 2011, 108 (15), 6032-6037.

Greenberg, Paul E, Andree-Anne Fournier, Tammy Sisitsky, Crystal T Pike, and Ronald C Kessler, "The economic burden of adults with major depressive disorder in the United States (2005 and 2010)," The Journal of Clinical Psychiatry, 2015, 76 (2), $155-162$.

Iancu, Ariella, Lisa Jaycox, Joie D. Acosta, Frank G. Straub, Samantha Iovan, Christopher Nelson, and Mahshid Abir, "After School Shootings, Children And Communities Struggle To Heal," Health Affairs, 2019.

Janosz, Michel, Isabelle Archambault, Linda S Pagani, Sophie Pascal, Alexandre J S Morin, and François Bowen, "Are there detrimental effects of witnessing school violence in early adolescence?," Journal of Adolescent Health, 2008, 43 (6), 600-608.

Krug, Etienne G, James A Mercy, Linda L Dahlberg, and Anthony B Zwi, "The world report on violence and health," The Lancet, 2002, 360 (9339), 1083-1088.

Levine, Phillip B and Robin McKnight, "Firearms and accidental deaths: Evidence from the aftermath of the Sandy Hook school shooting," Science, 2017, 358 (6368), 13241328.

Lowe, S R, J Blachman-Forshay, and K C Koenen, "Epidemiology of trauma and trauma-related disorders: trauma as a public health issue," in "Evidence-based treatments for trauma-related psychological disorders: A practical guide for clinicians," New York: Springer, 2015, pp. 11-40.

Lowe, Sarah R and Sandro Galea, "The mental health consequences of mass shootings," Trauma, Violence, \&3 Abuse, 2017, 18 (1), 62-82.

Mrug, Sylvie, Penny S Loosier, and Michael Windle, "Violence exposure across multiple contexts: Individual and joint effects on adjustment," American Journal of Orthopsychiatry, 2008, 78 (1), 70-84. 
Nader, Kathi, Robert Pynoos, Lynn Fairbanks, and Calvin Frederick, "Children's PTSD reactions one year after a sniper attack at their school," The American Journal of Psychiatry, 1990, 147 (11), 1526.

Pah, A. R., J. Hagan, A. L. Jennings, A. Jain, K. Albrecht, A. J. Hockenberry, and L. A. N. Amaral, "Economic insecurity and the rise in gun violence at US schools," Nature Human Behavior, 2017, 1 (2), 0040.

Pynoos, Robert S, Calvin Frederick, Kathi Nader et al., "Life threat and posttraumatic stress in school-age children," Archives of General Psychiatry, 1987, 44 (12), $1057-1063$.

Reardon, S. F., A. D. Ho, B. R. Shear, E. M. Fahle, D. Kalogrides, H. Jang, J. Buontempo, and R. Disalvo, "Stanford Education Data Archive (Version 3.0)," http://purl.stanford.edu/db586ns4974 2017.

Ross, Eric L, Sandeep Vijan, Erin M Miller, Marcia Valenstein, and Kara Zivin, "The Cost-Effectiveness of Cognitive Behavioral Therapy Versus Second-Generation Antidepressants for Initial Treatment of Major Depressive Disorder in the United States: A Decision Analytic Model," Annals of Internal Medicine, 2019.

Rowhani-Rahbar, A, DF Zatzick, and FP Rivara, "Long-lasting Consequences of Gun Violence and Mass Shootings," JAMA, 2019, 321 (18), 1765-1766.

Schwarz, Eitan D and Janice M Kowalski, "Malignant memories: PTSD in children and adults after a school shooting," Journal of the American Academy of Child \& Adolescent Psychiatry, 1991, 30 (6), 936-944.

_ and _, "Posttraumatic stress disorder after a school shooting: Effects of symptom threshold selection and diagnosis by DSM-III, DSM-III-R, or proposed DSM-IV," The American Journal of Psychiatry, 1991, 148 (5), 592.

_ and _, "Malignant memories: Reluctance to utilize mental health services after a disaster.," Journal of Nervous and Mental Disease, 1992.

_ and _, "Personality characteristics and posttraumatic stress symptoms after a school shooting.," Journal of Nervous and Mental Disease, 1992.

_, _, and Richard J McNally, "Malignant memories: Post-traumatic changes in memory in adults after a school shooting," Journal of Traumatic Stress, 1993, 6 (4), 545-553.

Sloan, Ira H, Ronald H Rozensky, Leslie Kaplan, and Stephen M Saunders, "A shooting incident in an elementary school: Effects of worker stress on public safety, mental health, and medical personnel," Journal of Traumatic Stress, 1994, 7 (4), 565-574.

Stretesky, Paul B and Michael J Hogan, "Columbine and student perceptions of safety: A quasi-experimental study," Journal of Criminal Justice, 2001, 29 (5), 429-443. 
Studdert, David M, Yifan Zhang, Jonathan A Rodden, Rob J Hyndman, and Garen J Wintemute, "Handgun acquisitions in California after two mass shootings," Annals of Internal Medicine, 2017, 166 (10), 698-706.

Travers, Á, T McDonagh, and A. Elklit, "Youth Responses to School Shootings: a Review," Current Psychiatry Reports, 2018, 20 (6), 47. 


\section{$6 \quad$ Figures and Tables}

Figure 1: Youth Antidepressant Use by Month Relative to School Shooting

(a) Fatal Shootings, 0-5 Miles

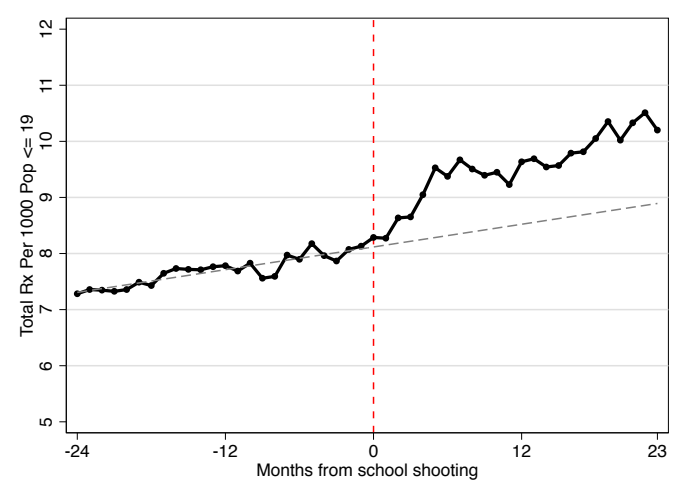

(c) Fatal Shootings, 10-15 Miles

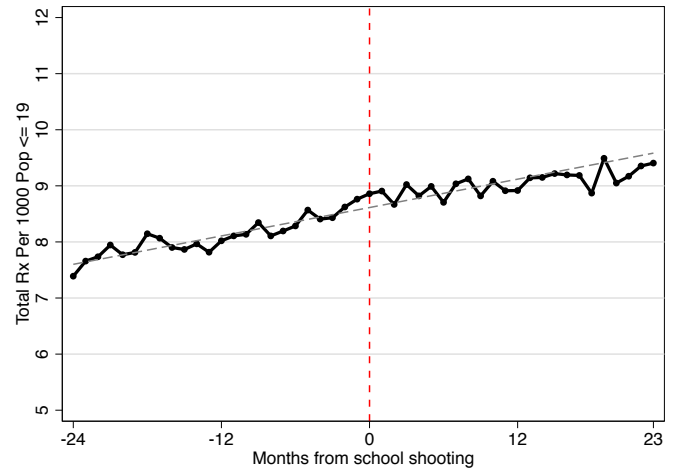

(b) Non-Fatal Shootings, 0-5 Miles

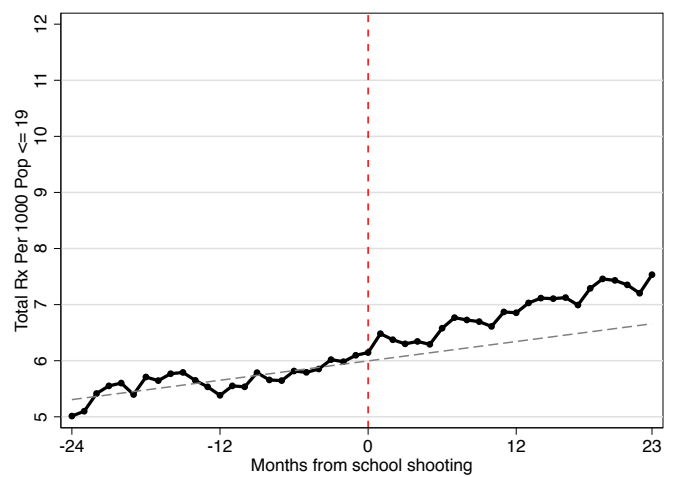

(d) Non-Fatal Shootings, 10-15 Miles

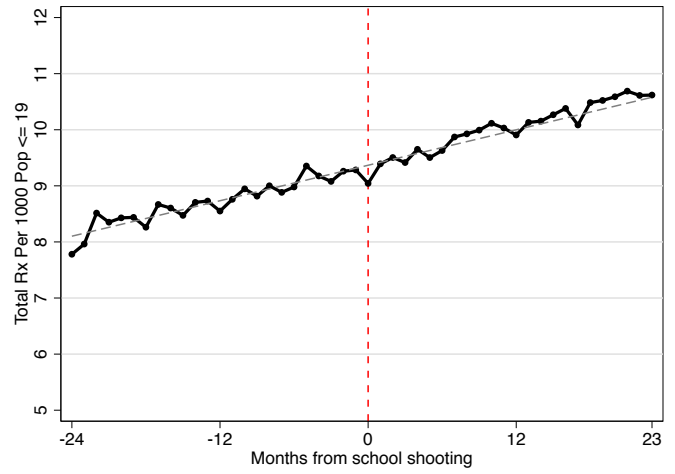

Notes: The solid black line in each subfigure shows the monthly number of antidepressant prescriptions written to individuals under age 20 by providers located either $0-5$ miles or $10-15$ miles from a school that experienced a shooting per 1,000 individuals under age 20 residing in these areas. The dashed gray line is a linear fit based on a regression that only uses pre-shooting observations. 
Figure 2: Effects of School Shootings on Youth Antidepressant Use

(a) Fatal Shootings

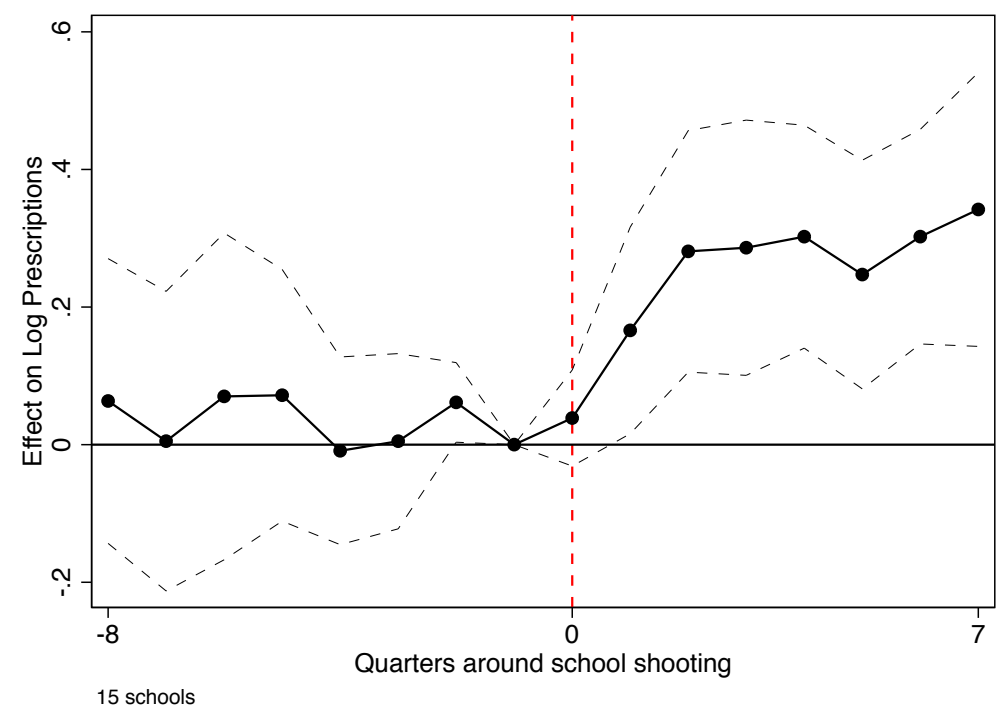

(b) Non-Fatal Shootings

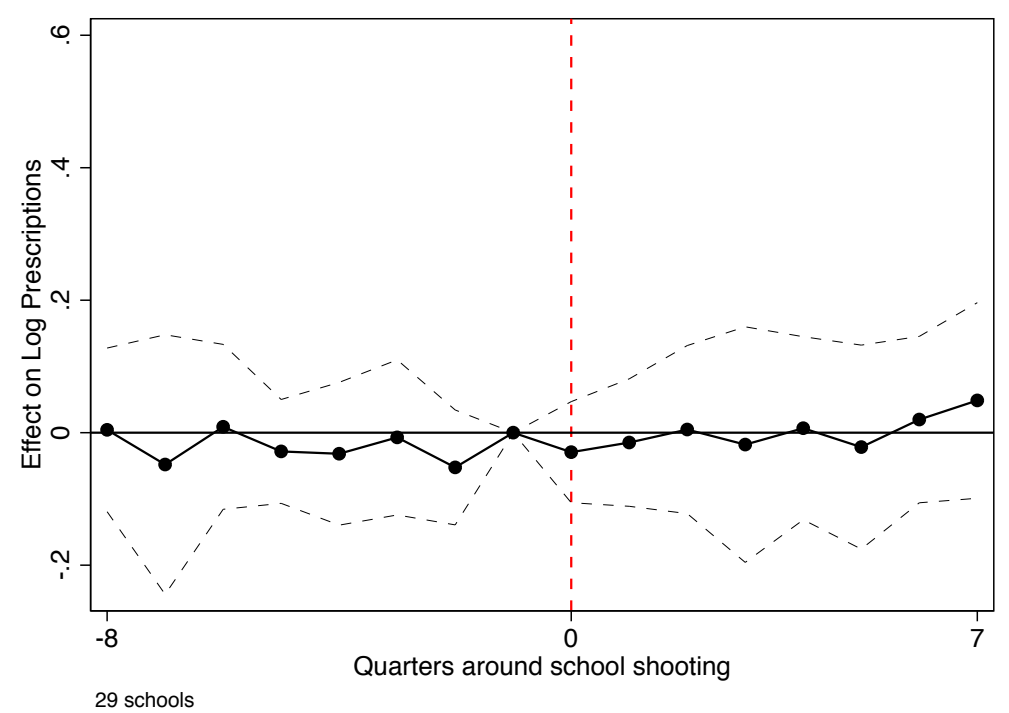

Notes: The above figures present output from estimation of Equation (2). In particular, we regress $\log$ antidepressant prescriptions for individuals under age 20 at the school-area-month level on quarterly event time indicators, quarterly event time indicators interacted with an indicator denoting shooting-exposed areas, month-by-year fixed effects, and school-by-area fixed effects. We run separate regressions for fatal (subfigure (a)) and non-fatal (subfigure (b)) school shootings. We plot the coefficients and 95\% confidence intervals on the interactions between quarterly event time indicators and the indicator denoting shooting-exposed areas; these coefficients represent the percentage difference in the number of antidepressant prescriptions written to individuals under age 20 between the shooting-exposed and reference areas in each of the quarters surrounding a school shooting relative to the quarter before the shooting. The shooting-exposed (reference) areas include providers practicing 0-5 (10-15) miles from an affected school. All regressions are weighted by school enrollment, and standard errors are clustered at the school-by-area level. 
Table 1: Descriptive Statistics

\begin{tabular}{lccccccc}
\hline & \multicolumn{3}{c}{ Shooting Schools } & & All Schools & \\
\cline { 2 - 3 } & $\begin{array}{c}\text { Any } \\
(1)\end{array}$ & Fatal & Non-Fatal & $p$-val & & p-val \\
& $(2)$ & $(3)$ & $(2)-(3)$ & $(5)$ & $(1)-(5)$ \\
\hline A. School Characteristics & & & & & & \\
\hline Total Enrollment (1000s) & 1.01 & 1.22 & 0.90 & 0.18 & 0.44 & 0.00 \\
Private School & 0.09 & 0.13 & 0.07 & 0.49 & 0.22 & 0.01 \\
High School & 0.50 & 0.40 & 0.55 & 0.35 & 0.15 & 0.00 \\
Share White & 0.45 & 0.49 & 0.43 & 0.66 & 0.59 & 0.00 \\
Share Black & 0.30 & 0.17 & 0.37 & 0.09 & 0.16 & 0.00 \\
Share Hispanic & 0.19 & 0.28 & 0.14 & 0.13 & 0.17 & 0.25 \\
Share Asian & 0.02 & 0.03 & 0.02 & 0.23 & 0.04 & 0.13 \\
Share Free/Reduced Lunch & 0.48 & 0.43 & 0.51 & 0.29 & 0.44 & 0.04 \\
Number Killed & 0.95 & 2.80 & 0.00 & 0.02 & & \\
Number Injured & 0.66 & 0.47 & 0.76 & 0.26 & & \\
Any Shooter Died & 0.14 & 0.20 & 0.10 & 0.39 & & \\
Age of Shooter & 20.39 & 25.60 & 18.46 & 0.09 & & \\
Male Shooter & 0.91 & 0.80 & 0.97 & 0.07 & & \\
\hline B. Monthly \# of Antidepressant Prescriptions Written to Youth Per & $\mathbf{1 , 0 0 0}$ \\
\hline 0-5 Miles & 13.33 & 11.52 & 13.60 & 0.00 & 11.58 & 0.00 \\
10-15 Miles & 9.48 & 8.86 & 10.20 & 0.00 & 5.19 & 0.00 \\
\hline Number of Schools & 44 & 15 & 29 & & 127,363 & \\
\hline
\end{tabular}

Notes: Columns (1)-(3) report average characteristics of schools in our analysis; Column (5) reports averages for all U.S. schools. Column (4) reports $p$-values from tests of differences in average characteristics between schools with fatal and non-fatal shootings. Column (6) reports $p$-values from tests of differences in average characteristics between schools with any shooting and all U.S. schools. Panel B reports the average monthly number of antidepressant prescriptions written to individuals under age 20 by providers practicing $0-5$ or 10-15 miles from a school per 1,000 individuals under age 20 living in the same area. Averages in Panel B are weighted by school enrollment. We used a 1\% random sample of U.S. schools when calculating average antidepressant prescription rates across all U.S. schools (Column (5) of Panel B; N=1,234). 
Table 2: Effects of School Shootings on Youth Antidepressant Use

\begin{tabular}{|c|c|c|c|c|}
\hline & \multicolumn{2}{|c|}{ Fatal Shootings } & \multicolumn{2}{|c|}{ Non-Fatal Shootings } \\
\hline & $\begin{array}{l}\text { 2-Year } \\
(1)\end{array}$ & $\begin{array}{c}\text { 3-Year } \\
(2)\end{array}$ & $\begin{array}{l}\text { 2-Year } \\
(3)\end{array}$ & $\begin{array}{l}\text { 3-Year } \\
(4)\end{array}$ \\
\hline \multicolumn{5}{|c|}{ A. Outcome: Log Antidepressant Prescriptions } \\
\hline Shooting-Exposed x Post & $\begin{array}{c}0.213^{* * *} \\
(0.064)\end{array}$ & $\begin{array}{c}0.245^{* * *} \\
(0.079)\end{array}$ & $\begin{array}{l}0.0187 \\
(0.060)\end{array}$ & $\begin{array}{l}0.0603 \\
(0.053)\end{array}$ \\
\hline \multicolumn{5}{|c|}{ B. Outcome: Antidepressant Prescription Rate per 1,000 } \\
\hline Shooting-Exposed x Post & $\begin{array}{l}1.982^{* *} \\
(0.940)\end{array}$ & $\begin{array}{l}2.645^{* *} \\
(1.241)\end{array}$ & $\begin{array}{c}1.674 \\
(1.219)\end{array}$ & $\begin{array}{c}0.348 \\
(0.701)\end{array}$ \\
\hline Effect Size as Proportion of Sample Mean & $0.206^{* *}$ & $0.297^{* *}$ & 0.163 & 0.037 \\
\hline $\begin{array}{l}\text { Number of Schools } \\
\text { Observations }\end{array}$ & $\begin{array}{c}15 \\
1412\end{array}$ & $\begin{array}{c}12 \\
1410\end{array}$ & $\begin{array}{c}29 \\
2601\end{array}$ & $\begin{array}{c}24 \\
2718\end{array}$ \\
\hline
\end{tabular}

Notes: The above table reports output from estimation of Equation (1). In particular, we regress measures of antidepressant prescriptions for individuals under age 20 at the school-area-month level on an indicator denoting months in or after a school shooting ("Post"), an interaction between the post indicator and an indicator denoting shooting-exposed areas, month-by-year fixed effects, and school-by-area fixed effects. We run separate regressions for fatal (Columns (1) and (2)) and non-fatal (Columns (3) and (4)) school shootings and include either a two-year (Columns (1) and (3)) or three-year (Columns (2) and (4)) follow-up window. In Panel A, the outcome is the log number of antidepressant prescriptions written to individuals under age 20; the reported coefficient in each column is therefore the percentage difference in the post-shooting change in the number of antidepressant prescriptions written to individuals under age 20 between the shooting-exposed and reference areas. In Panel B, the outcome is the antidepressant prescription rate per 1,000 individuals under 20; the reported coefficient in each column is therefore the difference in the post-shooting change in the antidepressant prescription rate per 1,000 individuals under age 20 between the shooting-exposed and reference areas. The third row in Panel B reports the effect size as a proportion of the sample mean of the outcome. The shooting-exposed (reference) areas include providers practicing 0-5 (10-15) miles from an affected school. All regressions are weighted by school enrollment, and standard errors (reported in parentheses) are clustered at the school-by-area level. Significance levels: ${ }^{*} \mathrm{p}<0.1 * * \mathrm{p}<0.05^{* * *} \mathrm{p}<0.01$ 
Table 3: Effects of Fatal School Shootings on Youth Antidepressant Use by Density of Mental Health Care Providers

\begin{tabular}{|c|c|c|c|c|c|c|c|}
\hline & \multirow{2}{*}{$\frac{\text { Baseline }}{(1)}$} & \multicolumn{3}{|c|}{ Linear interaction } & \multicolumn{3}{|c|}{ Tercile interaction } \\
\hline & & $(2)$ & $(3)$ & $(4)$ & $(5)$ & (6) & $(7)$ \\
\hline Exposed x Post & $\begin{array}{c}0.213^{* * *} \\
(0.064)\end{array}$ & $\begin{array}{c}0.316^{* *} \\
(0.117)\end{array}$ & $\begin{array}{c}0.343^{* * *} \\
(0.090)\end{array}$ & $\begin{array}{c}0.274^{* *} \\
(0.116)\end{array}$ & $\begin{array}{c}0.290^{* * *} \\
(0.103)\end{array}$ & $\begin{array}{c}0.426^{* * *} \\
(0.085)\end{array}$ & $\begin{array}{c}0.452^{* * *} \\
(0.090)\end{array}$ \\
\hline Exposed x Post x Prescriber Density & & $\begin{array}{l}-0.037 \\
(0.028)\end{array}$ & & $\begin{array}{c}0.058 \\
(0.046)\end{array}$ & & & \\
\hline Exposed x Post x Non-Prescriber Density & & & $\begin{array}{c}-0.039^{* *} \\
(0.017)\end{array}$ & $\begin{array}{c}-0.067^{* *} \\
(0.025)\end{array}$ & & & \\
\hline Exposed x Post x Mid-Tercile Prescriber Density & & & & & $\begin{array}{l}-0.189 \\
(0.113)\end{array}$ & & $\begin{array}{l}-0.129 \\
(0.097)\end{array}$ \\
\hline Exposed x Post x Top Tercile Prescriber Density & & & & & $\begin{array}{l}-0.142 \\
(0.151)\end{array}$ & & $\begin{array}{c}0.067 \\
(0.149)\end{array}$ \\
\hline Exposed x Post x Mid-Tercile Non-Prescriber Dens. & & & & & & $\begin{array}{c}-0.328^{* *} \\
(0.122)\end{array}$ & $\begin{array}{c}-0.332^{* *} \\
(0.124)\end{array}$ \\
\hline Exposed x Post x Top Tercile Non-Prescriber Dens. & & & & & & $\begin{array}{c}-0.348^{* * *} \\
(0.114)\end{array}$ & $\begin{array}{c}-0.399^{* * *} \\
(0.140)\end{array}$ \\
\hline Observations & 1,412 & 1,412 & 1,412 & 1,412 & 1,412 & 1,412 & 1,412 \\
\hline
\end{tabular}

Notes: The above table reports output from estimation of augmented versions of Equation (1). In particular, we regress log antidepressant prescriptions for individuals under age 20 at the school-area-month level on an indicator denoting months in or after a school shooting ("Post"); an interaction between the post indicator and an indicator denoting shooting-exposed areas; interactions between the post indicator, the shooting-exposed indicator, and county-level measures of the density of child mental health providers; month-by-year fixed effects; and school-by-area fixed effects. We include the density measures either as continuous variables (Columns (2)-(4)) or as indicators denoting terciles across shooting-exposed counties (Columns (5)-(7)). "Prescribers" include physicians in pediatrics, psychiatry, or family medicine; "Non-Prescribers" include psychologists and social workers. The shooting-exposed (reference) areas include providers practicing 0-5 (10-15) miles from an affected school. All regressions only consider fatal school shootings, consider a two-year follow-up window, and are weighted by school enrollment. Standard errors (reported in parentheses) are clustered at the school-by-area level. For ease of comparison, Column (1) replicates our baseline results from Table 2 . Significance levels: ${ }^{*} \mathrm{p}<0.1{ }^{* *} \mathrm{p}<0.05{ }^{* * *}$ $\mathrm{p}<0.01$ 


\section{ONLINE APPENDIX}

\section{A Supplementary Figures}

Figure A1: Shootings at U.S. Primary and Secondary Schools: April 1999-May 2018

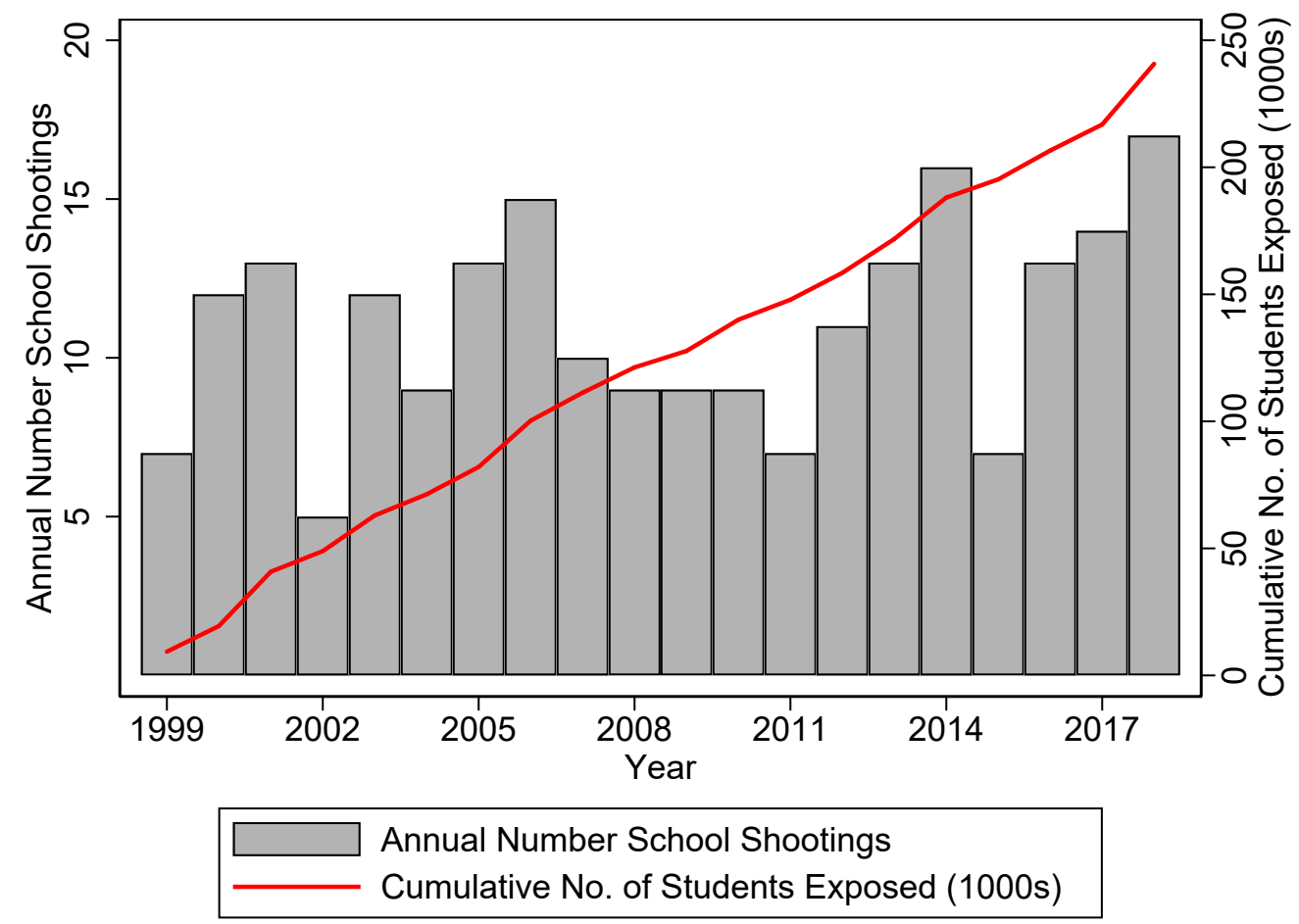

Notes: The bars depict the number of school shootings at primary and secondary schools in the United States in each calendar year over the period April 1999-May 2018; the line depicts the cumulative number of students who were enrolled in schools that experienced shootings over this period. Our main analysis uses data on school shootings between January 2008 and April 2013. Source: Washington Post database on school shootings, downloaded on June 20, 2018. 
Figure A2: Effects of School Shootings on Youth Antidepressant Use: 3-Year Follow-Up

(a) Fatal Shootings

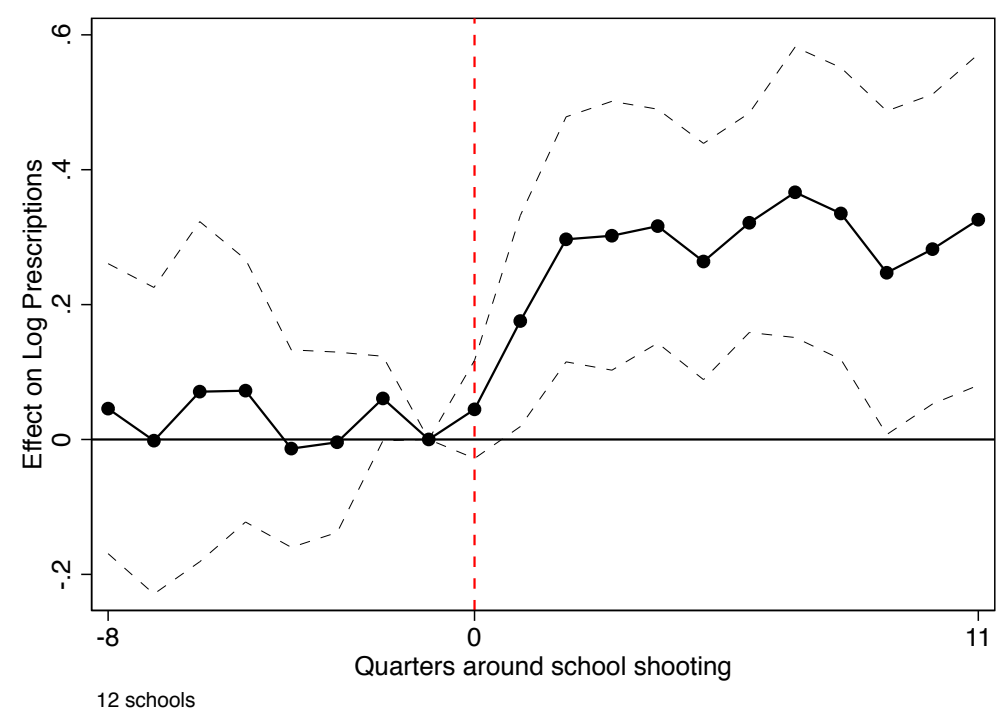

(b) Non-Fatal Shootings

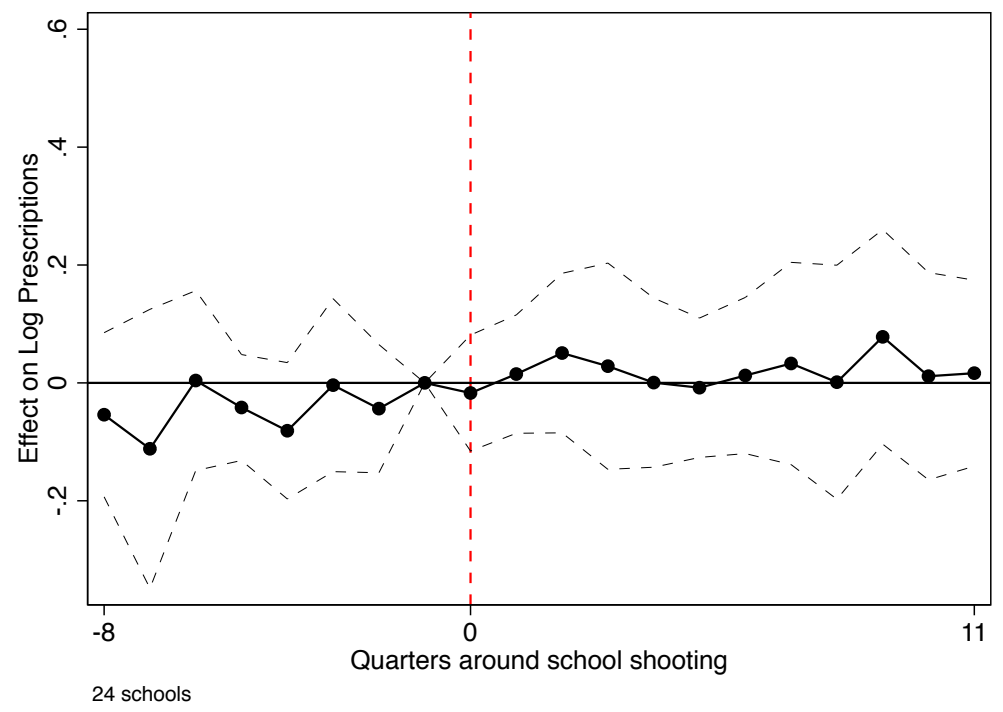

Notes: The above figures present output from estimation of Equation (2). In particular, we regress $\log$ antidepressant prescriptions for individuals under age 20 at the school-area-month level on quarterly event time indicators, quarterly event time indicators interacted with an indicator denoting shooting-exposed areas, month-by-year fixed effects, and school-by-area fixed effects. We run separate regressions for fatal (subfigure (a)) and non-fatal (subfigure (b)) school shootings. We plot the coefficients and 95\% confidence intervals on the interactions between quarterly event time indicators and the indicator denoting shooting-exposed areas; these coefficients represent the percentage difference in the number of antidepressant prescriptions written to individuals under age 20 between the shooting-exposed and reference areas in each of the quarters surrounding a school shooting relative to the quarter before the shooting. The shooting-exposed (reference) areas include providers practicing 0-5 (10-15) miles from an affected school. All regressions are weighted by school enrollment, and standard errors are clustered at the school-by-area level. 
Figure A3: Sensitivity of Estimates to Varying the Radius Defining Shooting-Exposed Areas

(a) Fatal Shootings

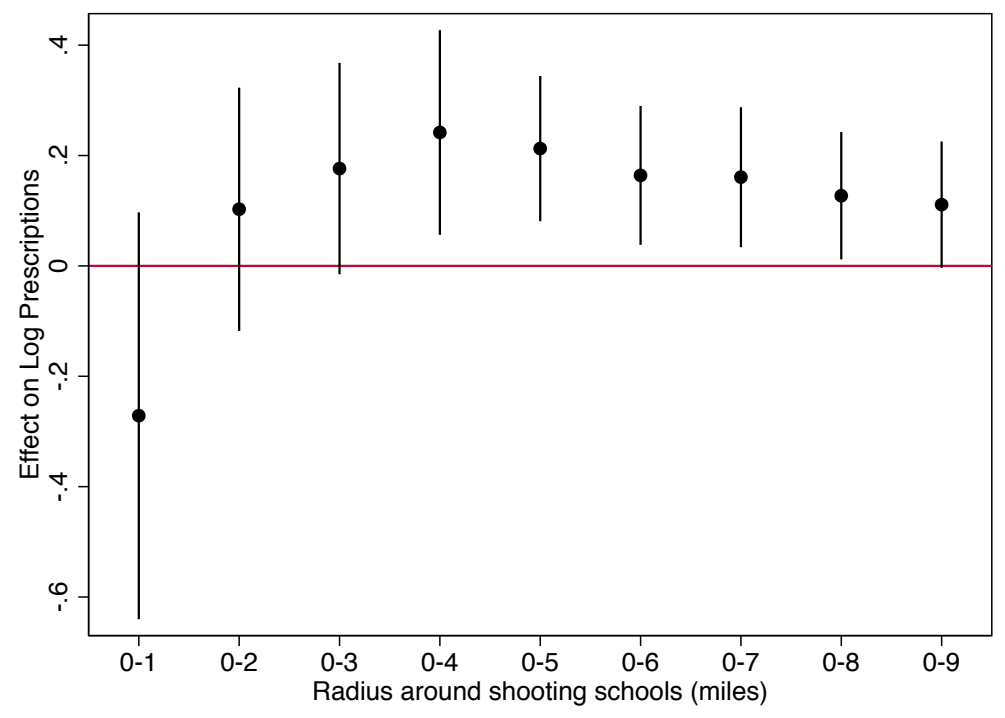

(b) Non-Fatal Shootings

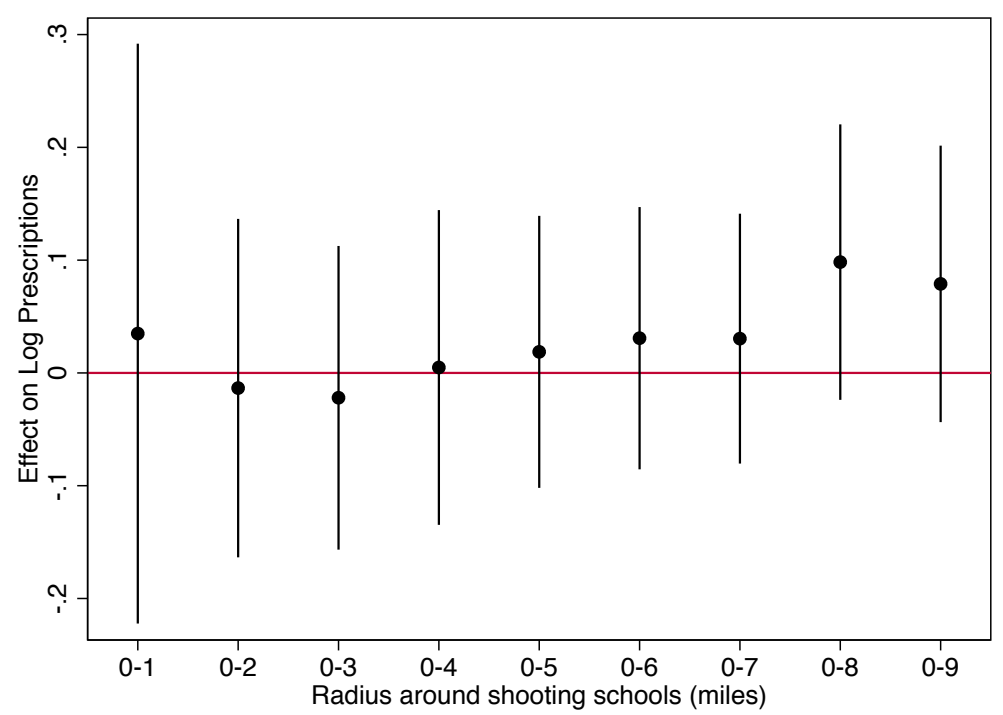

Notes: Each subfigure presents output from estimation of nine separate versions of Equation (1), in which we vary the definition of shooting-exposed areas to include providers located between 0-1 to 0-9 miles of an affected school. We hold the reference areas fixed at providers practicing 10-15 miles from an affected school in all specifications. We run these nine sets of regressions separately for fatal (subfigure (a)) and non-fatal (subfigure (b)) school shootings. We plot the coefficients and $95 \%$ confidence intervals on the interaction between the post indicator and the indicator denoting shooting-exposed areas; these coefficients represent the percentage difference in the post-shooting change in the number of antidepressant prescriptions written to individuals under age 20 between the shooting-exposed and reference areas. 
Figure A4: Effects of School Shootings on Youth Antidepressant Use: Alternative Control Groups

(a) Fatal Shootings

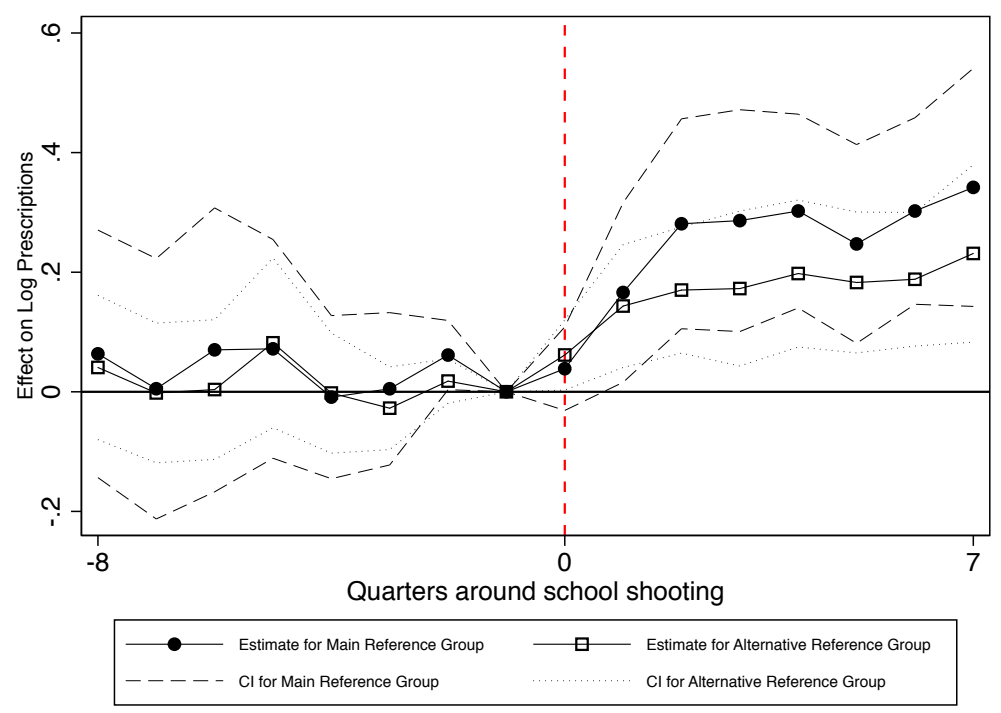

(b) Non-Fatal Shootings

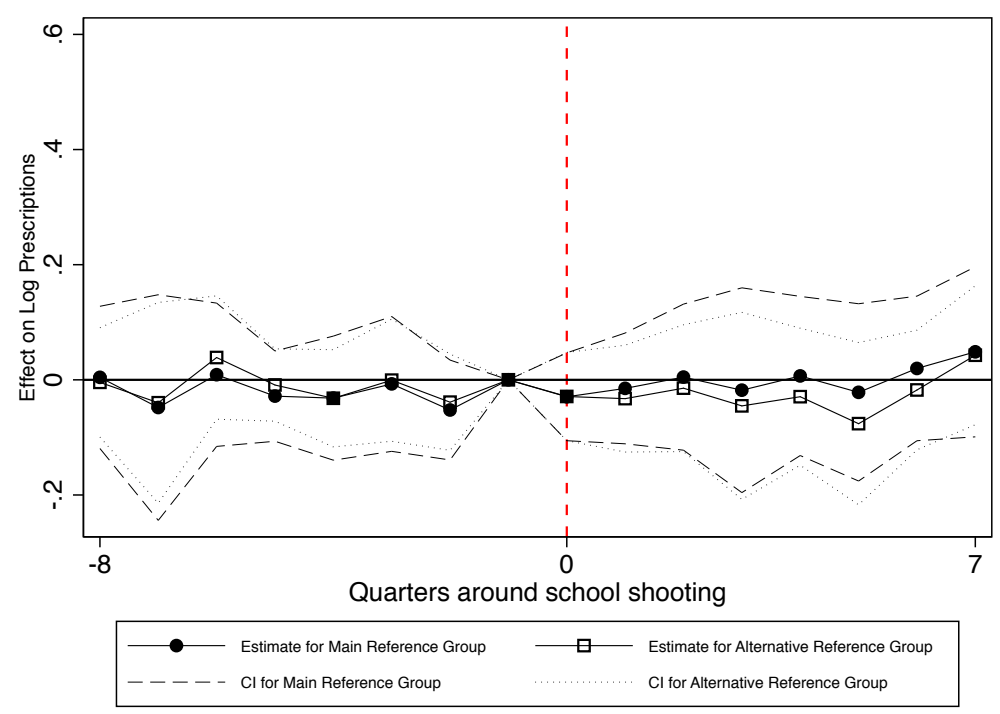

Notes: The above figures present overlaid output from estimation of Equation (2) and an event study analog of Equation (3). The main difference between the two specifications is the reference area: while Equation (2) compares log antidepressant prescriptions written by providers practicing $0-5$ miles from a school that experienced a shooting to those written by providers practicing 10-15 miles away, Equation (3) compares $\log$ antidepressant prescriptions written by providers practicing 0-5 miles from a school that experienced a shooting to those written by providers practicing 0-5 miles from observationally similar schools that did not experience a shooting. We run these alternative specifications separately for fatal (subfigure (a)) and non-fatal (subfigure (b)) school shootings. For each specification, we plot coefficients and $95 \%$ confidence intervals that represent the percentage difference in the post-shooting change in the number of antidepressant prescriptions written to individuals under age 20 between the shooting-exposed and reference areas. Details on how control schools are selected are provided in the text. 


\section{Figure A5: Placebo: Effects of School Shootings on Youth Opioid Use}

(a) Fatal Shootings

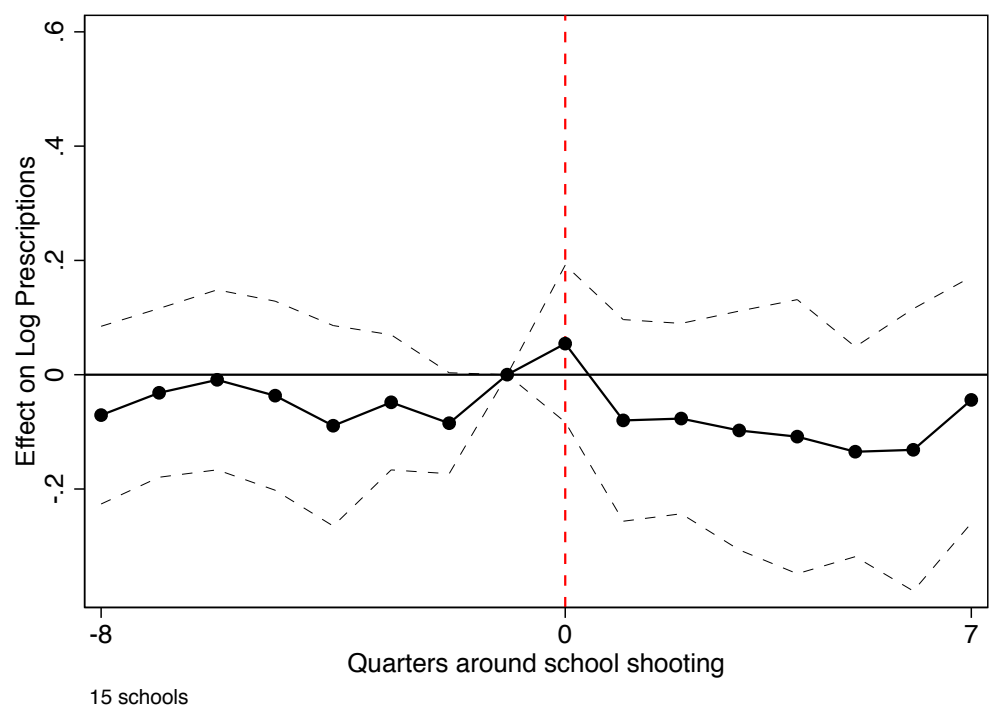

(b) Non-Fatal Shootings

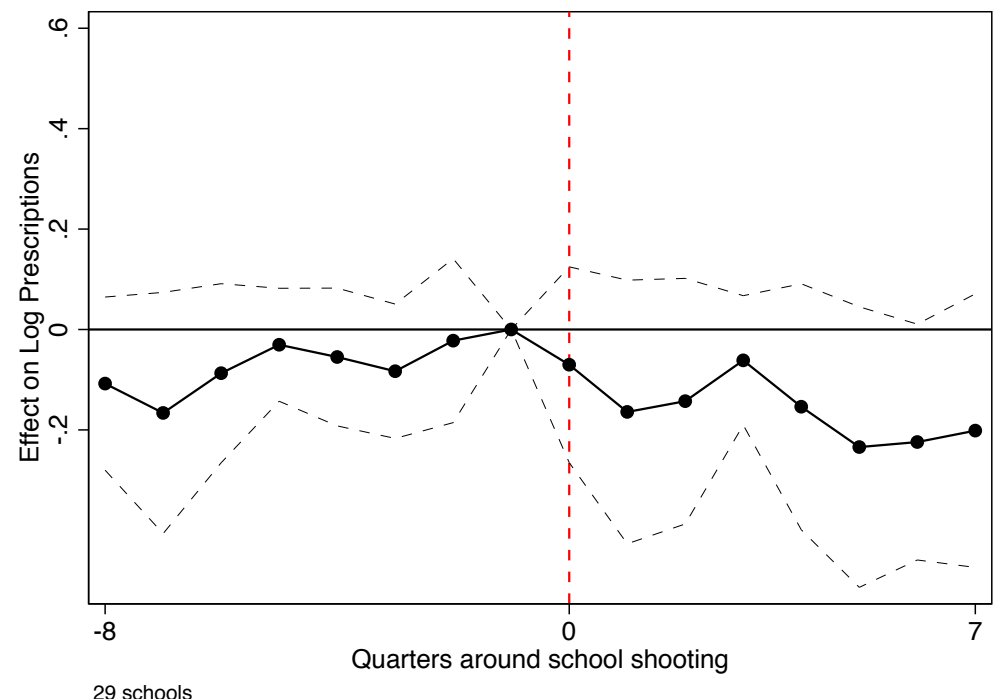

Notes: The above figures present output from estimation of Equation (2). In particular, we regress log opioid prescriptions for individuals under age 20 at the school-area-month level on quarterly event time indicators, quarterly event time indicators interacted with an indicator denoting shooting-exposed areas, month-byyear fixed effects, and school-by-area fixed effects. We run separate regressions for fatal (subfigure (a)) and non-fatal (subfigure (b)) school shootings. We plot the coefficients and $95 \%$ confidence intervals on the interactions between quarterly event time indicators and the indicator denoting shooting-exposed areas; these coefficients represent the percentage difference in the number of opioid prescriptions written to individuals under age 20 between the shooting-exposed and reference areas in each of the quarters surrounding a school shooting relative to the quarter before the shooting. The shooting-exposed (reference) areas include providers practicing 0-5 (10-15) miles from an affected school. All regressions are weighted by school enrollment, and standard errors are clustered at the school-by-area level. 
Figure A6: Effects of Fatal School Shootings on Adult Antidepressant Use

(a) Fatal Shootings

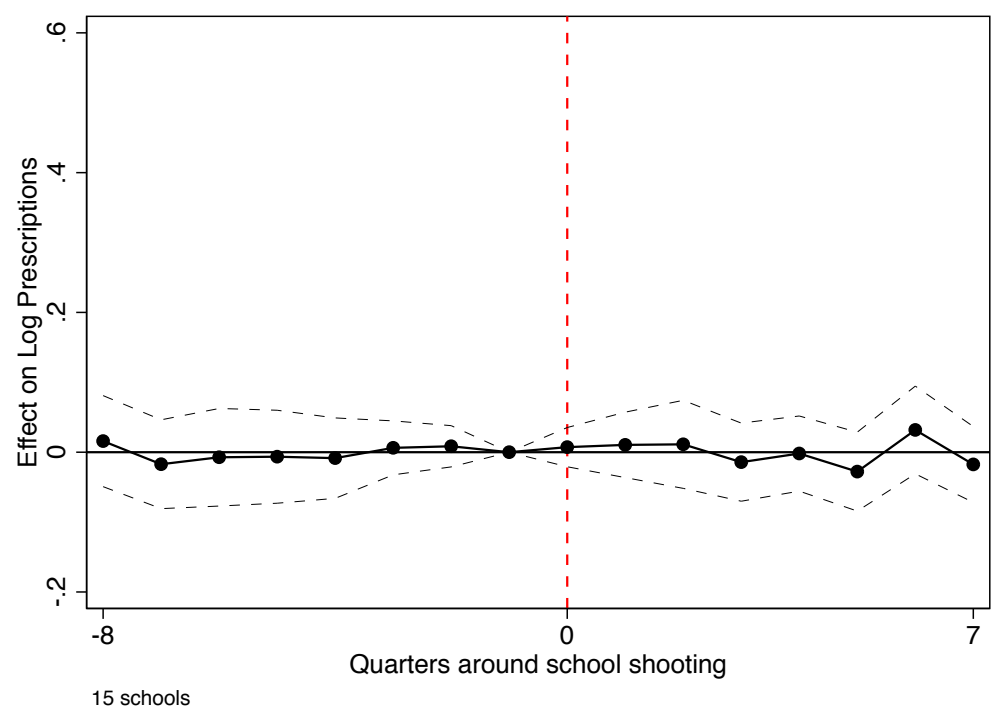

(b) Non-Fatal Shootings

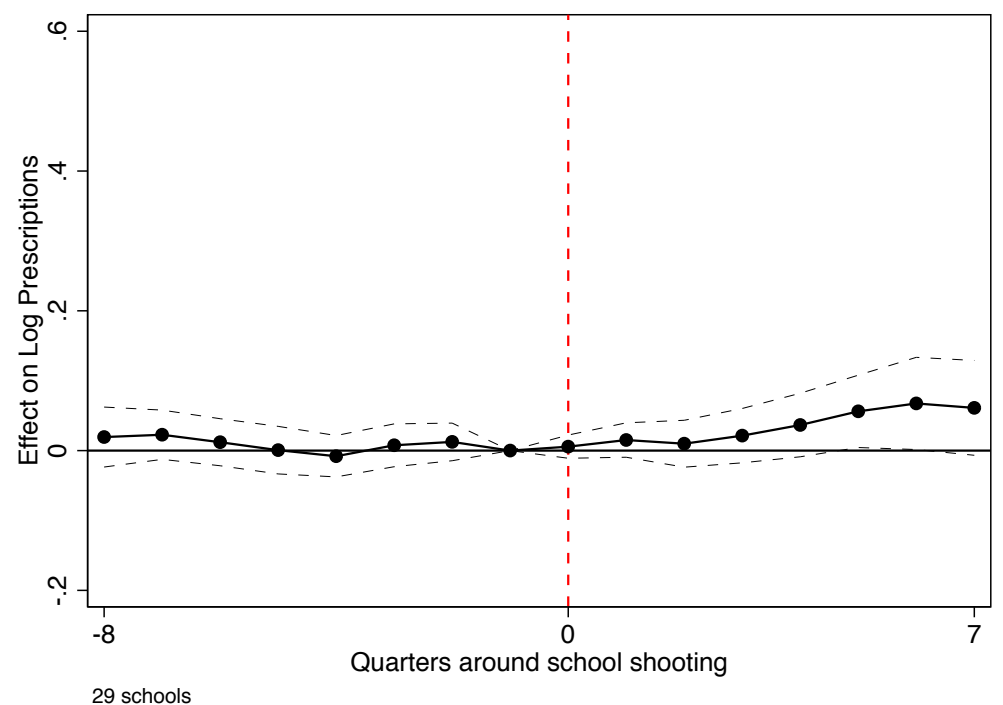

Notes: The above figures present output from estimation of Equation (2). In particular, we regress log antidepressant prescriptions for individuals aged 20 and older at the school-area-month level on quarterly event time indicators, quarterly event time indicators interacted with an indicator denoting shooting-exposed areas, month-by-year fixed effects, and school-by-area fixed effects. We run separate regressions for fatal (subfigure (a)) and non-fatal (subfigure (b)) school shootings. We plot the coefficients and $95 \%$ confidence intervals on the interactions between quarterly event time indicators and the indicator denoting shooting-exposed areas; these coefficients represent the percentage difference in the number of antidepressant prescriptions written to individuals aged 20 and older between the shooting-exposed and reference areas in each of the quarters surrounding a school shooting relative to the quarter before the shooting. The shooting-exposed (reference) areas include providers practicing 0-5 (10-15) miles from an affected school. All regressions are weighted by school enrollment, and standard errors are clustered at the school-by-area level. 
Figure A7: Correlation Between Provider Density Measures

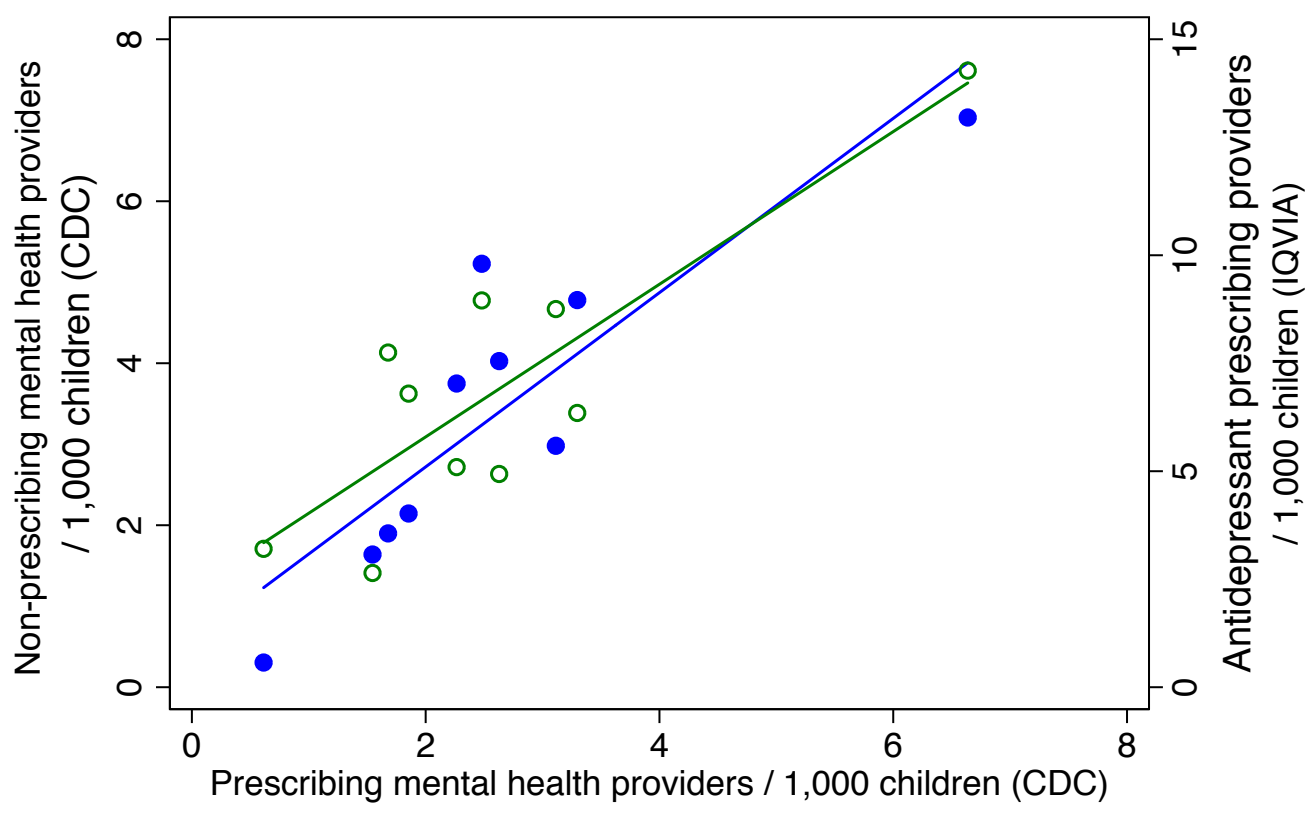

- Non-prescribing mental health providers (CDC)

- Antidepressant prescribing providers (IQVIA)

Notes: The above figure depicts the correlation between different measures of local provider density. The $x$-axis measures the county-level number of child mental health care providers who can prescribe medication (physicians in family medicine, pediatrics, and psychiatry) per 1,000 children aged 0-17 as reported by the CDC. The left $y$-axis measures the county-level number of child mental health care providers who traditionally cannot prescribe medication (psychologists and social workers) per 1,000 children aged 0-17 as reported by the CDC. The right $y$-axis measures the number of providers in the IQVIA data who prescribed at least one antidepressant to an individual under age 20 in 2010 in each school's shooting-exposed area per 1,000 individuals under age 20. The points represent deciles of schools in our main analysis grouped according to densities of prescribers from the CDC; the lines are linear fits of these points. 
Figure A8: Effects of Fatal School Shootings on Youth Antidepressant Use by Density of Mental Health Care Providers

(a) Density of Prescribers

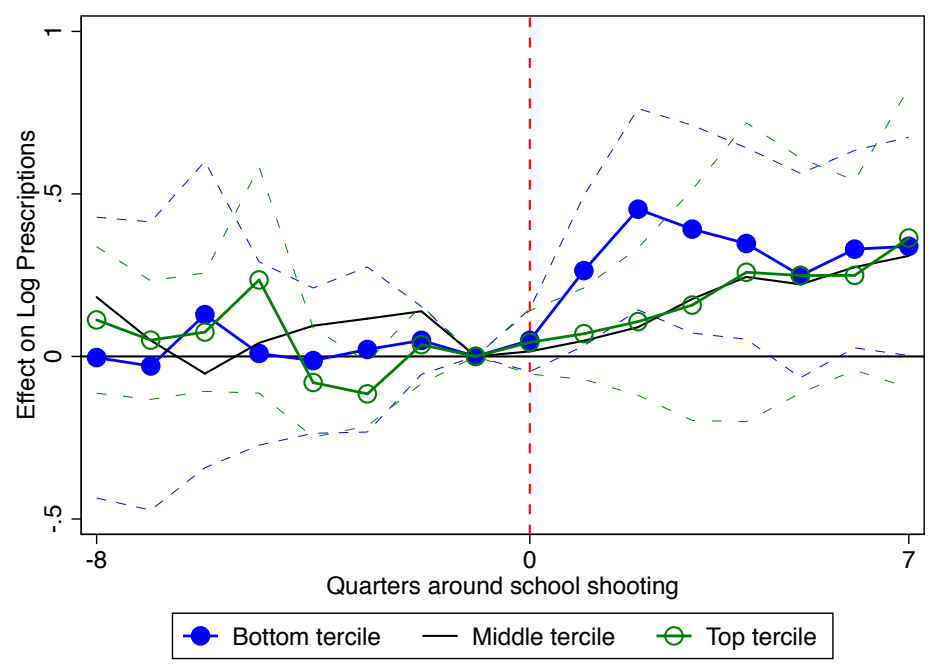

(b) Density of Non-Prescribers

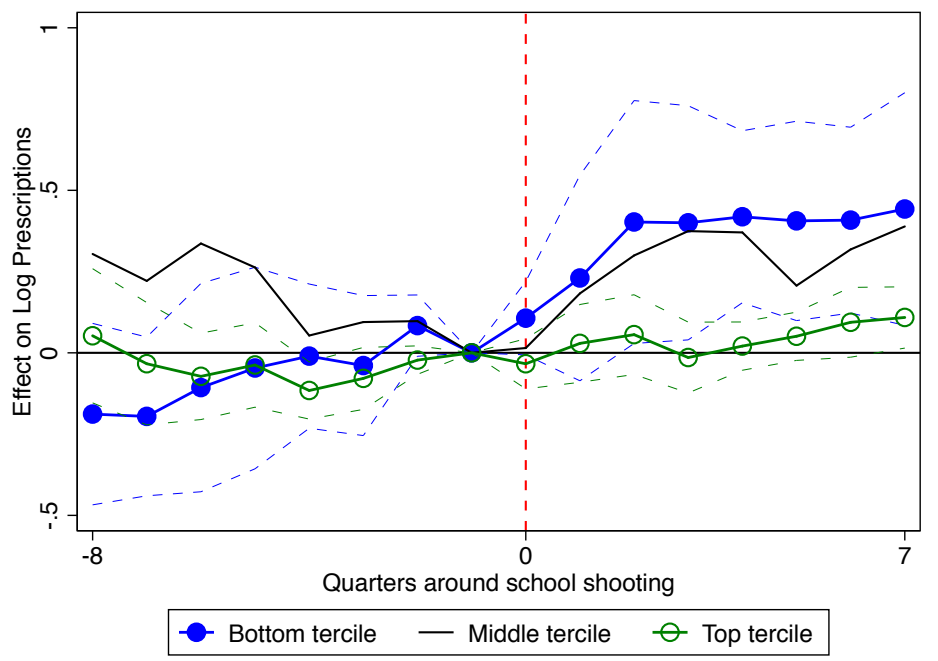

Notes: The above figures present output from estimation of augmented versions of Equation (2). In particular, we regress log antidepressant prescriptions for individuals under age 20 at the school-area-month level on quarterly event time indicators; quarterly event time indicators interacted with an indicator denoting shooting-exposed areas; interactions between quarterly event time indicators, the shooting-exposed indicator, and terciles of county-level measures of the density of child mental health providers; month-by-year fixed effects; and school-by-area fixed effects. We include the density measures separately for "Prescribers" (physicians in family medicine, pediatrics, and psychiatry per 1,000 children aged 0-17; subfigure (a)) and "Non-Prescribers" (psychologists and social workers per 1,000 children aged 0-17; subfigure (b)). We plot the coefficients and $95 \%$ confidence intervals on the interactions between quarterly event time indicators, the indicator denoting shooting-exposed areas, and terciles of county-level measures of child mental health provider densities; these coefficients represent the percentage difference in the number of antidepressant prescriptions written to individuals under age 20 between the shooting-exposed and reference areas in each of the quarters surrounding a school shooting relative to the quarter before the shooting. The shootingexposed (reference) areas include providers practicing 0-5 (10-15) miles from an affected school. All regressions are weighted by school enrollment, and standard errors are clustered at the school-by-area level. 


\section{B Supplementary Tables}

Table A1: School Shootings in Main Analysis Sample

\begin{tabular}{|c|c|c|c|c|}
\hline School & Date & \#Killed & \#Injured & Shooter Died? \\
\hline Alisal High School & Oct 2010 & 1 & 0 & No \\
\hline Apostolic Revival Center and Christian School & Jan 2013 & 1 & 0 & No \\
\hline Armin Jahr Elementary School & Feb 2012 & 0 & 1 & No \\
\hline Cape Fear High School & Oct 2011 & 0 & 1 & No \\
\hline Carolina Forest High School & Oct 2009 & 1 & 0 & No \\
\hline Chardon High School & Feb 2012 & 3 & 3 & No \\
\hline Crossroads Charter High School & Jan 2008 & 0 & 1 & No \\
\hline Cummings Middle School & Jan 2012 & 1 & 0 & No \\
\hline Deer Creek Middle School & Feb 2010 & 0 & 2 & No \\
\hline Dillard High School & Nov 2008 & 1 & 0 & No \\
\hline Discovery Middle School & Feb 2010 & 1 & 0 & No \\
\hline E.O. Green Junior High School & Feb 2008 & 1 & 0 & No \\
\hline Episcopal School of Jacksonville & Mar 2012 & 1 & 0 & Yes \\
\hline Hamilton High School & Feb 2008 & 0 & 1 & No \\
\hline John Muir Elementary School & Feb 2009 & 0 & 0 & No \\
\hline Kelly Elementary School & Oct 2010 & 0 & 2 & No \\
\hline La Salle High School & Apr 2013 & 0 & 0 & No \\
\hline Larose-Cut Off Middle School & May 2009 & 0 & 0 & Yes \\
\hline LeFlore High School & Mar 2012 & 0 & 0 & No \\
\hline Louisiana Schnell Elementary School & Feb 2011 & 1 & 0 & No \\
\hline Marinette High School & Nov 2010 & 0 & 0 & Yes \\
\hline Martinsville West Middle & Mar 2011 & 0 & 1 & No \\
\hline Mary Scroggs Elementary School & May 2012 & 1 & 0 & No \\
\hline Mattituck Junior-Senior High School & Oct 2009 & 0 & 1 & No \\
\hline Millard South High School & Jan 2011 & 1 & 2 & Yes \\
\hline Mitchell High School & Feb 2008 & 0 & 1 & No \\
\hline Normal Community High School & Sep 2012 & 0 & 0 & No \\
\hline North Forest High School & Jan 2012 & 0 & 1 & No \\
\hline Notre Dame Elementary School & Feb 2008 & 0 & 1 & Yes \\
\hline Perry Hall High School & Aug 2012 & 0 & 1 & No \\
\hline Price Middle School & Jan 2013 & 0 & 1 & No \\
\hline Ribault High School & Mar 2009 & 0 & 0 & No \\
\hline Roosevelt High School & Apr 2008 & 1 & 0 & No \\
\hline Ross Elementary School & Apr 2011 & 0 & 2 & No \\
\hline Sandy Hook Elementary School & Dec 2012 & 26 & 2 & Yes \\
\hline Sheeler Charter High School & Apr 2011 & 0 & 1 & No \\
\hline Socastee High School & Sep 2010 & 0 & 1 & No \\
\hline South Gate High School & May 2010 & 0 & 1 & No \\
\hline Stamford Academy & Sep 2009 & 0 & 0 & No \\
\hline Sullivan Central High School & Aug 2010 & 1 & 0 & No \\
\hline Taft Union High School & Jan 2013 & 0 & 2 & No \\
\hline Virginia Randolph Community High School & Sep 2009 & 0 & 0 & No \\
\hline Walpole Elementary School & Feb 2012 & 0 & 0 & No \\
\hline Woodrow Wilson High School & Apr 2010 & 0 & 0 & No \\
\hline
\end{tabular}

Notes: The above table lists the 44 shootings at U.S. primary and secondary schools included in our main analysis. We include schools that experienced their first shooting since April 1999 over our sample window (January 2008 to April 2013) and had at least one antidepressant prescription written by a provider within five miles of the school in each month in the two years surrounding the shooting. Source: Washington Post database on school shootings, downloaded on June 20, 2018. 
Table A2: Predicting School Shootings

\begin{tabular}{|c|c|c|c|c|c|c|}
\hline \multirow{2}{*}{$\begin{array}{l}\text { Dep Var: Indicator Denoting School Shooting } \\
\text { Suburban }\end{array}$} & \multicolumn{2}{|c|}{$\begin{array}{c}\text { Any } \\
(1) \\
\end{array}$} & \multicolumn{2}{|c|}{$\begin{array}{c}\text { Fatal } \\
(2)\end{array}$} & \multicolumn{2}{|c|}{$\begin{array}{c}\text { Non-Fatal } \\
(3)\end{array}$} \\
\hline & $-0.474^{* *}$ & $(0.183)$ & $-0.702^{* *}$ & $(0.218)$ & 0.177 & $(0.356)$ \\
\hline Town & -0.291 & $(0.252)$ & -0.261 & $(0.284)$ & -0.332 & $(0.546)$ \\
\hline Rural & $-0.485^{*}$ & $(0.239)$ & $-0.738^{*}$ & $(0.294)$ & 0.145 & $(0.440)$ \\
\hline Per Pupil Expenditures $(\$ 10,000 \mathrm{~s})$ & -0.022 & $(0.450)$ & -0.178 & $(0.521)$ & 0.410 & $(0.870)$ \\
\hline Per Pupil Instructor Expenditures $(\$ 10,000 \mathrm{~s})$ & -1.370 & $(0.884)$ & -1.125 & $(1.005)$ & -2.235 & $(1.804)$ \\
\hline District Socioeconomic Status & -0.189 & $(0.129)$ & -0.191 & $(0.152)$ & -0.165 & $(0.245)$ \\
\hline District 3rd-8th Academic Achievement (Mean) & 0.231 & $(0.410)$ & 0.537 & $(0.484)$ & -0.652 & $(0.770)$ \\
\hline District 3rd-8th Academic Achievement (Slope) & -2.451 & $(1.844)$ & -2.030 & $(2.108)$ & -4.503 & $(3.699)$ \\
\hline Total Enrollment (1000s) & $0.816^{* *}$ & $(0.085)$ & $0.728^{* *}$ & $(0.100)$ & $0.982^{* *}$ & $(0.127)$ \\
\hline Private School & $-0.898^{* *}$ & $(0.322)$ & $-1.229^{* *}$ & $(0.430)$ & -0.305 & $(0.499)$ \\
\hline Share White Students & $-2.594^{* *}$ & $(0.606)$ & $-2.912^{* *}$ & $(0.724)$ & $-1.888^{*}$ & $(1.076)$ \\
\hline Share Black Students & 0.015 & $(0.567)$ & 0.179 & $(0.670)$ & -0.664 & $(1.054)$ \\
\hline Share Hispanic Students & $-2.014^{* *}$ & $(0.616)$ & $-2.190^{* *}$ & $(0.733)$ & -1.464 & $(1.093)$ \\
\hline Share Asian Students & $-6.292^{* *}$ & $(1.840)$ & $-5.213^{* *}$ & $(1.924)$ & $-10.488^{*}$ & $(4.707)$ \\
\hline Share Free/Reduced Price Lunch & $-1.391^{* *}$ & $(0.430)$ & $-1.223^{*}$ & $(0.503)$ & $-2.110^{* *}$ & $(0.815)$ \\
\hline High School Only & $1.424^{* *}$ & $(0.159)$ & $1.614^{* *}$ & $(0.185)$ & $0.962^{* *}$ & $(0.297)$ \\
\hline Constant & $-3.581^{* *}$ & $(0.678)$ & $-3.749^{* *}$ & $(0.796)$ & $-5.099 * *$ & $(1.272)$ \\
\hline R-Squared & 0.1 & & 0.16 & & 0.1 & \\
\hline Number Schools & 1173 & 306 & 1172 & & 117 & 148 \\
\hline
\end{tabular}

Notes: The above table reports output from logistic regressions of an indicator denoting whether a school experienced a school shooting since 1999 on a range of school and district-level characteristics. The sample includes all primary and secondary schools in the United States. We run separate regressions for all (Columns (1)), fatal (Column (2)), and non-fatal (Columns (3)) school shootings. Note that the race/ethnicity categories are not mutually exclusive. Standard errors are reported in parentheses. Significance levels: ${ }^{*} \mathrm{p}<0.1$ ** $\mathrm{p}<0.05^{* * *} \mathrm{p}<0.01$ 
Table A3: Effects of School Shootings on Youth Antidepressant Use: Alternative Control Groups

\begin{tabular}{|c|c|c|c|c|}
\hline & \multicolumn{2}{|c|}{ Fatal Shootings } & \multicolumn{2}{|c|}{ Non-Fatal Shootings } \\
\hline & $\begin{array}{c}\text { 2-Year } \\
\quad(1)\end{array}$ & $\begin{array}{c}\text { 3-Year } \\
\quad(2)\end{array}$ & $\begin{array}{c}\text { 2-Year } \\
(3)\end{array}$ & $\begin{array}{c}\text { 3-Year } \\
(4)\end{array}$ \\
\hline Post & $\begin{array}{l}0.154^{* * *} \\
(0.0450)\end{array}$ & $\begin{array}{l}0.165^{* * *} \\
(0.0449)\end{array}$ & $\begin{array}{l}-0.0145 \\
(0.0521)\end{array}$ & $\begin{array}{c}0.00192 \\
(0.0461)\end{array}$ \\
\hline Number of Schools & 114 & 112 & 129 & 124 \\
\hline Observations & 11643 & 11547 & 12326 & 12086 \\
\hline
\end{tabular}

Notes: The above table reports output from estimation of Equation (3). In particular, we regress log monthly antidepressant prescriptions written for individuals under age 20 by providers practicing $0-5$ miles from a school on an indicator denoting months in or after a school shooting (set to zero for all observations from control schools), month-by-year fixed effects, and school fixed effects. The sample includes schools that experienced a school shooting and observationally similar schools that did not experience a shooting; see the text for more information on how control schools are selected. We run separate regressions for fatal (Columns (1) and (2)) and non-fatal (Columns (3) and (4)) school shootings and include either a two-year (Columns (1) and (3)) or three-year (Columns (2) and (4)) follow-up window. The reported coefficient in each column represents the percentage difference in the post-shooting change in the number of antidepressant prescriptions written to individuals under age 20 by providers practicing $0-5$ miles from shooting-exposed and control schools. All regressions are weighted by school enrollment, and standard errors (reported in parentheses) are clustered by school. Significance levels: ${ }^{*} \mathrm{p}<0.1 * * \mathrm{p}<0.05 * * * \mathrm{p}<0.01$ 
Table A4: Effects of Fatal School Shootings on Youth Antidepressant Use: "Leave-One-Out" Robustness

\begin{tabular}{|c|c|c|c|c|c|c|c|c|c|c|c|}
\hline & Main & No AL & No CA & No CT & No FL & No NE & No NC & $\mathrm{No} \mathrm{OH}$ & No SC & No TN & No TX \\
\hline \multicolumn{12}{|c|}{ A. Two-Year Follow-Up Window } \\
\hline $\begin{array}{l}\text { Shooting-Exp. } \\
\text { x Post }\end{array}$ & $\begin{array}{c}0.213^{* * *} \\
(0.064)\end{array}$ & $\begin{array}{c}0.213^{* * *} \\
(0.068)\end{array}$ & $\begin{array}{c}0.267^{* * *} \\
(0.079)\end{array}$ & $\begin{array}{c}0.221^{* * *} \\
(0.065)\end{array}$ & $\begin{array}{c}0.211^{* * *} \\
(0.075)\end{array}$ & $\begin{array}{c}0.236^{* * *} \\
(0.069)\end{array}$ & $\begin{array}{c}0.223^{* * *} \\
(0.065)\end{array}$ & $\begin{array}{c}0.214^{* * *} \\
(0.068)\end{array}$ & $\begin{array}{c}0.164^{* * *} \\
(0.056)\end{array}$ & $\begin{array}{c}0.196^{* * *} \\
(0.065)\end{array}$ & $\begin{array}{r}0.196^{* * *} \\
(0.063)\end{array}$ \\
\hline Observations & 1,412 & 1,316 & 1,028 & 1,316 & 1,124 & 1,316 & 1,316 & 1,316 & 1,316 & 1,316 & 1,344 \\
\hline \multicolumn{12}{|c|}{ B. Three-Year Follow-Up Window } \\
\hline $\begin{array}{l}\text { Shooting-Exp. } \\
\text { x Post }\end{array}$ & $\begin{array}{c}0.245^{* * *} \\
(0.078)\end{array}$ & $\begin{array}{c}0.246^{* * *} \\
(0.083)\end{array}$ & $\begin{array}{c}0.352^{* * *} \\
(0.079)\end{array}$ & $\begin{array}{c}0.245^{* * *} \\
(0.078)\end{array}$ & $\begin{array}{l}0.249^{* *} \\
(0.093)\end{array}$ & $\begin{array}{c}0.262^{* * *} \\
(0.088)\end{array}$ & $\begin{array}{c}0.245^{* * *} \\
(0.078)\end{array}$ & $\begin{array}{c}0.244^{* * *} \\
(0.083)\end{array}$ & $\begin{array}{l}0.189^{* *} \\
(0.071)\end{array}$ & $\begin{array}{l}0.223^{* *} \\
(0.081)\end{array}$ & $\begin{array}{r}0.228^{* * *} \\
(0.078)\end{array}$ \\
\hline Observations & 1,410 & 1,290 & 930 & 1,410 & 1,170 & 1,290 & 1,410 & 1,290 & 1,290 & 1,290 & 1,320 \\
\hline \multicolumn{12}{|c|}{ C. Two-Year Follow-Up Window, Heterogeneity by Provider Density } \\
\hline Exposed x Post & $\begin{array}{l}0.27^{* *} \\
(0.12)\end{array}$ & $\begin{array}{c}0.27^{* *} \\
(0.12)\end{array}$ & $\begin{array}{c}0.38^{* * *} \\
(0.14)\end{array}$ & $\begin{array}{l}0.28^{* *} \\
(0.12)\end{array}$ & $\begin{array}{l}0.25^{*} \\
(0.13)\end{array}$ & $\begin{array}{l}0.28^{* *} \\
(0.11)\end{array}$ & $\begin{array}{c}0.67^{* * *} \\
(0.19)\end{array}$ & $\begin{array}{l}0.27^{* *} \\
(0.12)\end{array}$ & $\begin{array}{l}0.19^{*} \\
(0.11)\end{array}$ & $\begin{array}{c}0.30^{* *} \\
(0.13)\end{array}$ & $\begin{array}{l}0.23^{* *} \\
(0.11)\end{array}$ \\
\hline Exposed x Post x & 0.06 & 0.07 & 0.03 & 0.05 & 0.07 & 0.07 & 0.02 & 0.06 & 0.06 & 0.02 & 0.07 \\
\hline $\begin{array}{l}\text { Prescriber Density } \\
\text { Exposed x Post x }\end{array}$ & $\begin{array}{c}(0.05) \\
-0.07^{* *}\end{array}$ & $\begin{array}{c}(0.04) \\
-0.07^{* * *}\end{array}$ & $\begin{array}{c}(0.05) \\
-0.05^{* *}\end{array}$ & $\begin{array}{c}(0.05) \\
-0.06^{* *}\end{array}$ & $\begin{array}{c}(0.05) \\
-0.07^{* * *}\end{array}$ & $\begin{array}{c}(0.04) \\
-0.07^{* * *}\end{array}$ & $\begin{array}{c}(0.06) \\
-0.18^{* * *}\end{array}$ & $\begin{array}{c}(0.05) \\
-0.07^{* *}\end{array}$ & $\begin{array}{c}(0.04) \\
-0.06^{* *}\end{array}$ & $\begin{array}{l}(0.08) \\
-0.05\end{array}$ & $\begin{array}{c}(0.04) \\
-0.07^{* * *}\end{array}$ \\
\hline Non-Prescriber Dens. & $(0.03)$ & $(0.03)$ & $(0.02)$ & $(0.03)$ & $(0.02)$ & $(0.02)$ & $(0.05)$ & $(0.03)$ & $(0.02)$ & $(0.04)$ & $(0.02)$ \\
\hline Observations & 1,412 & 1,316 & 1,028 & 1,316 & 1,124 & 1,316 & 1,316 & 1,316 & 1,316 & 1,316 & 1,344 \\
\hline
\end{tabular}

Notes: The above table reports output from estimation of Equation (1) (Panels A and B) and augmented versions of Equation (1) (Panel C). Column (1) reports our baseline coefficients; the subsequent columns show how the coefficients change when we drop each state included in our analysis. In Panel A, we use a two-year follow-up window; in Panel B, we use a three-year follow-up window. Panel C uses a two-year follow-up window and includes interactions with the density of prescribing and non-prescribing mental health care providers. See the notes under Tables 2 and 3 for more details on each specification. Significance levels: ${ }^{*} \mathrm{p}<0.1 * * \mathrm{p}<0.05 * * * \mathrm{p}<0.01$ 
Table A5: Effects of Fatal School Shootings on Youth Antidepressant Use by Density of Mental Health Care Providers (IQVIA)

\begin{tabular}{|c|c|c|c|c|c|c|c|}
\hline & \multirow{2}{*}{$\frac{\text { Baseline }}{(1)}$} & \multicolumn{3}{|c|}{ Linear interaction } & \multicolumn{3}{|c|}{ Tercile interaction } \\
\hline & & $(2)$ & $(3)$ & $(4)$ & $(5)$ & $(6)$ & $(7)$ \\
\hline Exposed x Post & $\begin{array}{c}0.213^{* * *} \\
(0.064)\end{array}$ & $\begin{array}{c}0.249^{* * *} \\
(0.081)\end{array}$ & $\begin{array}{c}0.343^{* * *} \\
(0.090)\end{array}$ & $\begin{array}{c}0.338^{* * *} \\
(0.077)\end{array}$ & $\begin{array}{c}0.314^{* * *} \\
(0.069)\end{array}$ & $\begin{array}{c}0.426^{* * *} \\
(0.085)\end{array}$ & $\begin{array}{c}0.451^{* * *} \\
(0.070)\end{array}$ \\
\hline Exp. x P. x Prescriber Density (IQVIA) & & $\begin{array}{c}-0.005 \\
(0.007)\end{array}$ & & $\begin{array}{c}0.017 \\
(0.010)\end{array}$ & & & \\
\hline Exp. x P. x Non-Prescriber Density (CDC) & & & $\begin{array}{r}-0.039^{* *} \\
(0.017)\end{array}$ & $\begin{array}{c}-0.077^{* *} \\
(0.028)\end{array}$ & & & \\
\hline Exp. x P. x Mid-Tercile Prescriber Density (IQVIA) & & & & & $\begin{array}{c}-0.261^{* * *} \\
(0.092)\end{array}$ & & $\begin{array}{c}-0.199^{*} \\
(0.105)\end{array}$ \\
\hline Exp. x P. x Top Tercile Prescriber Density (IQVIA) & & & & & $\begin{array}{c}0.039 \\
(0.152)\end{array}$ & & $\begin{array}{c}-0.004 \\
(0.113)\end{array}$ \\
\hline Exp. x P. x Mid-Tercile Non-Prescriber Dens. (CDC) & & & & & & $\begin{array}{c}-0.328^{* *} \\
(0.122)\end{array}$ & $\begin{array}{c}-0.277^{* * *} \\
(0.087)\end{array}$ \\
\hline Exp. x P. x Top Tercile Non-Prescriber Dens. (CDC) & & & & & & $\begin{array}{c}-0.348^{* * *} \\
(0.114)\end{array}$ & $\begin{array}{c}-0.200 \\
(0.137)\end{array}$ \\
\hline Observations & 1,412 & 1,412 & 1,412 & 1,412 & 1,412 & 1,412 & 1,412 \\
\hline
\end{tabular}

Notes: The above table reports output from estimation of augmented versions of Equation (1). In particular, we regress log antidepressant prescriptions for individuals under age 20 at the school-area-month level on an indicator denoting months in or after a school shooting ("Post"); an interaction between the post indicator and an indicator denoting shooting-exposed areas; interactions between the post indicator, the shooting-exposed indicator, and measures of the density of child mental health providers; month-by-year fixed effects; and school-by-area fixed effects. We include the density measures either as continuous variables (Columns (2)-(4)) or as indicators denoting terciles across shooting-exposed counties (Columns (5)-(7)). "Prescriber Density" denotes the number of providers in the IQVIA data who prescribed at least one antidepressant to an individual under age 20 in 2010 in each school's shooting-exposed area per 1,000 individuals under age 20; "Non-Prescriber Density" denotes the county-level number of psychologists and social workers in 2015 per 1,000 children aged 0-17 as reported by the CDC. The shooting-exposed (reference) areas include providers practicing 0-5 (10-15) miles from an affected school. All regressions only consider fatal school shootings, consider a two-year follow-up window, and are weighted by school enrollment. Standard errors (reported in parentheses) are clustered at the school-by-area level. For ease of comparison, Column (1) replicates our baseline results from Table 2. Significance levels: ${ }^{*} \mathrm{p}<0.1{ }^{* *} \mathrm{p}<0.05{ }^{* * *} \mathrm{p}<0.01$ 